\title{
Survival after aortic root replacement with a stentless xenograft is determined by patient characteristics
}

Hanna H. Dagnegård, MD, ${ }^{\mathrm{a}, \mathrm{b}, \mathrm{c}}$ Kirstine Bekke, MD, ${ }^{\mathrm{a}}$ Solveig M. Kolseth, MD, PhD, ${ }^{\mathrm{d}}$ Natalie Glaser, MD, PhD, ${ }^{\text {, f }}$ Christoffer Wallén, MD, ${ }^{\mathrm{g}}$ Ismail El-Hamamsy, MD, PhD, ${ }^{\text {h }}$ Kristjan O. Vidisson, MD, ${ }^{i}$ Asbjørn S. Lie, ${ }^{d}$ Jan B. Valentin, MSc ${ }^{j}$ Ulrik Sartipy, MD, ${ }^{\mathrm{f}, \mathrm{k}}$ Rune Haaverstad, MD, ${ }^{\mathrm{d}}$ Farkas Vanky, MD, ${ }^{\mathrm{g}}$ Laurence Lefebvre, ${ }^{\mathrm{h}}$ Tomas Gudbjartsson, MD, ${ }^{\mathrm{i}}$ Søren P. Johnsen, MD, ${ }^{j}$ Lars Søndergaard, MD, ${ }^{b, c}$ Gustav H. Thyregod, MD, PhD, ${ }^{a}$ Jens T. Lund, MD, ${ }^{1}$ Nikolaj Ihlemann, MD, PhD, ${ }^{b}$ and Morten H. Smerup, $\mathrm{MD}^{\mathrm{a}, \mathrm{c}}$

\section{ABSTRACT}

Objectives: Our objective was to examine intermediate-term survival and reinterventions in unselected patients, stratified according to indication, who received a Freestyle (Medtronic Inc, Minneapolis, Minn) bioprosthesis as a full aortic root replacement.

Methods: Data from medical records were retrospectively collected for patients who had aortic root replacement using Freestyle bioprostheses between 1999 and 2018 at 6 North-Atlantic centers. Survival status was extracted from national registries and results stratified according to indication for surgery.

Results: We included 1030 implantations in 1008 patients with elective indications for surgery: aneurysm (39.8\%), small root (8.3\%), and other (13.8\%), and urgent/ emergent indications: endocarditis (26.7\%) and Stanford type A aortic dissection (11.4\%). Across indications, $46.3 \%$ were nonelective cases and 34.0\% were reoperations. Median age was 66.0 (interquartile range, 58.0-71.8) years and median follow-up was 5.0 (interquartile range, 2.6-7.9) years. Thirty-day mortality varied from $2.9 \%$ to $27.4 \%$ depending on indication. Intermediate survival for 90 -day survivors with elective indications were not different from the general population standardized for age and sex $(P=.95, .83$, and .16 for aneurysms, small roots, and other, respectively). In contrast, patients with endocarditis and type $A$ dissection had excess mortality $(P<.001)$. Freedom from valve reinterventions was $95.0 \%$ and $94.4 \%$ at 5 and 8 years, respectively. In all, 52 patients (5.2\%) underwent reinterventions, most because of endocarditis.

Conclusions: At intermediate term follow-up this retrospective study provides further support for the use of the Freestyle bioprosthesis in the real-world setting of diverse, complex, and often high-risk aortic root replacement and suggests that outcome is determined by patient and disease, rather than by prosthesis, characteristics. (J Thorac Cardiovasc Surg 2022;164:1712-24)

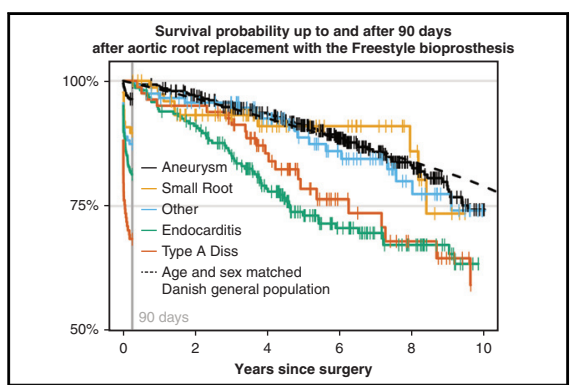

Survival after aortic root replacement with the Freestyle bioprosthesis (Medtronic Inc, Minneapolis, Minn) versus the Danish general population.

CENTRAL MESSAGE

Survival after Freestyle (Med-

tronic Inc, Minneapolis, Minn)

bioprosthesis aortic root

replacement resembles the general population for low-risk cases; outcome is thus explained by patient- and disease-related factors rather than the prosthesis per se.

\section{PERSPECTIVE}

This study provides support for the use of the Freestyle (Medtronic Inc, Minneapolis, Minn) bioprosthesis in the diverse indications in the realworld setting of often high-risk aortic root replacement. Our data corroborate the notion that indication influences outcome greatly and show that prosthesis characteristics are compatible with intermediate-term survival in low-risk cases corresponding to the general population.

See Commentaries on pages 1725 and 1726.
From the a Department of Cardiothoracic Surgery, ${ }^{\mathrm{b}}$ Department of Cardiology, Rigshospitalet, University Hospital of Copenhagen, Copenhagen, Denmark; ' Department of Clinical Medicine, Copenhagen University, Copenhagen, Denmark; ${ }^{\mathrm{d}}$ Department of Heart Disease, Haukeland University Hospital and University of Bergen,

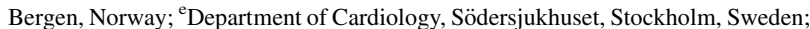
${ }^{\mathrm{f}}$ Department of Molecular Medicine and Surgery, Karolinska Institutet, Stockholm,
Sweden; ${ }^{\mathrm{g}}$ Department of Cardiothoracic and Vascular Surgery, Heart Centre, Department of Health, Medicine and Caring Sciences, Linköping University, Linköping, Sweden; 'hontreal Heart Institute, University of Montreal, Montreal, Quebec, Canada; ${ }^{\mathrm{i}}$ Department of Cardiothoracic Surgery, Landspítali University Hospital, Faculty of Medicine, University of Iceland, Reykjavik, Iceland; ${ }^{j}$ Danish Center for Clinical Health Services Research (DACS), Department of Clinical 


\section{Abbreviations and Acronyms \\ BMI = body mass index \\ CI $=$ confidence interval \\ CT $=$ computed tomography}

EuroSCORE $=$ European System for Cardiac

Operative Risk Evaluation

PVE $=$ prosthetic valve infective endocarditis

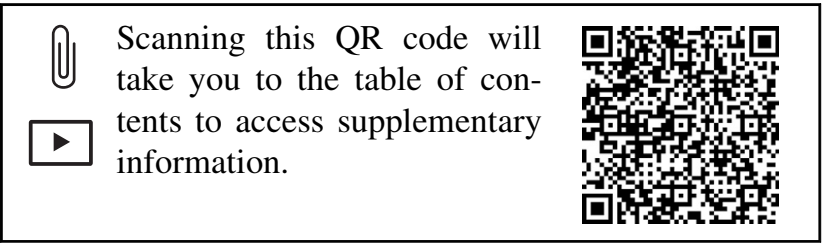

The Freestyle bioprosthesis (Medtronic Inc, Minneapolis, Minn) is a stentless porcine aortic root xenograft prosthesis that can be used in patients with a range of severe aortic root diseases. These include aneurysms, aortic dissections, and aortic root or prosthetic valve endocarditis, but also in patients in whom aortic root replacement solves technically complex problems such as small annuli and reoperative surgery of the aortic root or valve. ${ }^{1-3}$ Stentless xenografts have superior hemodynamics compared with most stented bioprostheses and the Freestyle has shown equal durability and survival compared with other bioprostheses at up to 15 years follow-up. ${ }^{3-6}$

However, the existing literature primarily regards selected populations from highly specialized centers. Hence, Freestyle performance in the most common setting of small-to-medium sized centers with unselected patients has not been determined. We therefore conducted a study including 6 North Atlantic institutions. The objective was to examine clinical outcomes, including overall survival and reinterventions, after Freestyle aortic root replacement, stratified according to indication.

\section{METHODS}

\section{Study Design and Patients}

This observational study included Freestyle aortic root replacements from 1999 to 2018 at 6 institutions: Rigshospitalet, University Hospital of Copenhagen (Copenhagen), Denmark; Karolinska University Hospital

Medicine, Aalborg University and Aalborg University Hospital, Aalborg, Denmark; ${ }^{\mathrm{k}}$ Department of Cardiothoracic Surgery, Karolinska University Hospital, Stockholm, Sweden; and ${ }^{\mathrm{l} C a r d i o}$ Thoracic Surgical Department, Green Lane Division, Auckland City Hospital, Auckland, New Zealand.

This work was supported by in-house resources only, at each participating site. Received for publication Feb 11, 2021; revisions received June 8, 2021; accepted for publication July 1, 2021; available ahead of print July 17, 2021.

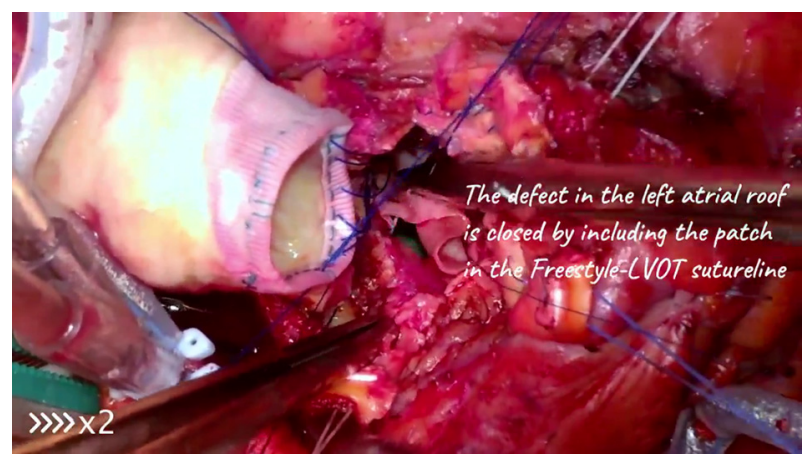

VIDEO 1. This is a video of a redo aortic root replacement in a 76-yearold woman who received an aortic valve bioprosthesis 2 months previously because of aortic valve stenosis. The postoperative course was complicated by mediastinitis, and she has now presented with prosthetic valve endocarditis including vegetations on the valve and in the left ventricular outflow tract. The video shows the explantation of the bioprosthesis and the resection of infected tissue. It then moves on to the reconstruction of the resulting defect in the left ventricular outflow tract and left atrial roof with a bovine pericardial patch. This is followed by the implantation of a full root Freestyle (Medtronic Inc, Minneapolis, Minn) bioprosthesis including the fashioning and reimplantation of the coronary buttons (the coronary ostia, with a cuff of aortic tissue). The case exemplifies one of the complex endocarditis cases, which are included in the endocarditis group in this article. Video available at: https://www.jtcvs.org/article/S0022-5223(21) 01042-4/fulltext.

(Stockholm), Sweden; Haukeland University Hospital (Bergen), Norway; Linköping University Hospital (Linköping), Sweden; Montreal Heart Institute (Montreal), Canada; and Landspítali University Hospital of Iceland (Reykjavik), Iceland. The participating centers were sole providers of cardiac surgery in each health region. The inclusion criterion was full root implantation of a Freestyle prosthesis in the aortic position. Patients were identified in local registries and those lost to follow-up within 30 days were excluded, thus including patients who died or had a reintervention before 30 days. Medical records were reviewed for baseline and perioperative data. The study was conducted in accordance with the Declaration of Helsinki, and ethical approval was obtained for all sites (Appendix E1).

\section{Surgical Indications and Technique}

We categorized surgical indications to reflect differences in patient characteristics and operative complexity. Primarily elective categories were: (1) aortic root aneurysm (aneurysm), (2) aortic valve replacement in patients with a small aortic annulus and risk of prosthesis-patient mismatch (small root), (3) predominantly reoperative aortic valve surgery or bail-out solution after failed attempted aortic root or valve procedures, both a priori characterized by long cross-clamp time and technical complexity (other). Urgent categories were: (4) native or prosthetic (PVE) valve infective endocarditis, aortic root abscess formation, or a combination (endocarditis, shown in Video 1); and (5) Stanford type A aortic dissection requiring aortic root replacement (type A dissection). The Freestyle was implanted

Address for reprints: Hanna H. Dagnegård, MD, Department of Cardiothoracic Surgery, The Heart Centre, Kontorafsnit 2152, Rigshospitalet, Blegdamsvej 9, 2100 Copenhagen O, Denmark (E-mail: hanna.dagnegaard@ regionh.dk). $0022-5223$

Copyright $(2021$ The Authors. Published by Elsevier Inc. on behalf of The American Association for Thoracic Surgery. This is an open access article under the CC BY license (http://creativecommons.org/licenses/by/4.0/).

https://doi.org/10.1016/j.jtcvs.2021.07.011 
using a modified Bentall approach with the proximal suture line technique and orientation performed at the surgeon's discretion. Running sutures were used for the coronary buttons and also for the anastomosis distal to the native ascending aorta or to a vascular prosthesis.

\section{Institutional Characteristics and Practice}

The participating institutions have a yearly volume varying between institutions and over time from 200 to approximately 2000 adult cardiac surgery cases per year and 2-10 surgeons per institution, giving a case load per surgeon ranging from 50 to 300 per year. In all centers, aortic root replacement might be performed by any on-staff surgeon, but complex cases as well as elective aortic root surgery have to a varying degree been concentrated on fewer hands. All participating institutions had the possibility of using a homograft, but most lacked in-house supply throughout the study period and thus generally needed to order a homograft in advance for the specific case. Montreal had access to homografts at all times, Bergen had a local homograft storage up to 2009, and Copenhagen keeps a small storage of only a few grafts in different sizes. The choice ultimately falls on the surgeon. The strategy for postoperative anticoagulation and antiplatelet therapy is similar across institutions; in recent times biological prostheses including the Freestyle patients are only given acetylsalicylic acid but in the first part of the study most institutions gave 2-3 months of warfarin treatment. None of the institutions has differentiated the Freestyle from other biological prostheses in their anticoagulant or antiplatelet regimens.

\section{Outcomes}

Early complications were reoperation for bleeding or tamponade, perioperative myocardial infarction as defined in Valve Academic Research Consortium-2, postoperative cerebrovascular events, and permanent pacemaker implantation within 30 days from surgery (see definitions in the Appendix E1). ${ }^{7}$ Survival status was extracted from civil registries, which guarantee complete and accurate status for domestic residents, except for very recent deaths, which might be registered with a few weeks' delay. Reinterventions were found according to medical record review up until 2019 and divided into those that were secondary to prosthetic valve failure (valve-related) or those caused by coronary artery pathology (coronary). Pseudoaneurysm formation in relation to the Freestyle bioprosthesis was considered valve-related. Because Copenhagen is a national referral site for complex cases, complete Copenhagen reintervention data was ensured using the civil registry number to cross-link with the Danish National Patient Registry in addition to the medical record review. Patients from Copenhagen or Montreal who were also included in a cross-sectional analysis with cardiac computed tomography (CT) were followed up to the date of the study CT imaging, thus not including findings on the CT imaging or ensuing clinical events, all of which have been previously reported. $^{8}$

\section{Statistical Analysis}

Continuous variables are presented as median with interquartile range, and categorical variables are presented as percentages and frequencies. Body mass index (BMI) is presented as categorical and continuous data. Patients lost to follow-up were censored at the time of their last clinical visit. Kaplan-Meier estimated survival curves were truncated when a minimum of $10 \%$ of the group remained at risk and compared using a log rank test. Significant time interaction between indication and time compromised the proportional hazards assumption. We therefore performed a post hoc landmark analysis (ie, survival of all patients up to 90 days after surgery, and for 90 day-survivors to end of follow-up). Cumulative risk of reintervention was visualized using the Aalen-Johansen estimator with death as competing risk. Hazard ratios and $95 \%$ confidence intervals (CIs) were estimated using Cox regression, and follow-up time was truncated when all groups had at least $10 \%$ remaining at risk. Results were stratified according to indication. Adjusted analysis of the full cohort was enabled using multiple imputation
(10 data sets) of missing values ( $<5 \%$ ) using fully conditional specification and chained equations (Stef van Buuren, 2020; mice: multivariate imputation by chained equations. R package version 3.9.0) with the use of Rubin's rule, and conditioned on event, event times, and variables known to influence survival and durability: indication, age, center for surgery, sex, preoperative significant coronary artery disease, presence of atrial fibrillation, and estimated glomerular filtration rate. The Danish general population was chosen as a representative reference for the entire study population; survival was obtained from the Human Mortality Database, and standardized for sex, age, and date of birth through the $\mathrm{R}$ package CuRe (Lasse Hjort Jakobsen, 2020; CuRe: parametric cure model estimation. $\mathrm{R}$ package version 1.0.0.), and compared with study data using the log rank test. Subgroup analysis of survival was performed per sex. All analyses were performed with $\mathrm{R}$ version 3.6.1 (R Foundation for Statistical Computing, Vienna, Austria).

\section{RESULTS}

We included 1030 implantations in 1008 patients (Copenhagen, $\mathrm{n}=445$; Stockholm, $\mathrm{n}=208$; Bergen, $\mathrm{n}=143$; Linköping, $\mathrm{n}=98$; Montreal, $\mathrm{n}=94$; and Reykjavik, $n=43$ ). Seven patients were excluded because of unavailable records or $<30$ days to censoring. Twenty-five nonresidents and emigrants were lost to follow-up $(2.5 \%)$. Median follow-up of survival was 5.0 years (interquartile range, 2.6-7.9; total range, 0-17.5 years). Elective indication frequencies were: aneurysm $39.8 \%(\mathrm{n}=410)$, small root $8.3 \%(\mathrm{n}=86)$, and other $13.8 \%(\mathrm{n}=142)$. Nonelective were: endocarditis $26.7 \%(\mathrm{n}=275$; of these $46.5 \%$ had PVE with root abscess, $24.0 \%$ had PVE without abscess, and $25.8 \%$ had native valve infective endocarditis with root abscess), and type A dissection $(11.4 \%, \mathrm{n}=117)$. All indications were represented at all centers, but with varying distribution (Figure E1). Median age was 66.0 years (interquartile range, $58.0-71.8$ years); $31.4 \%$ of the patients were 60 years or younger. The proportion of nonelective surgery was $46.3 \%$, and $34.0 \%$ were reoperations. Tables 1 and E1 shows baseline characteristics per indication, Tables E2 and E3 show them according to sex, and preoperative characteristics are shown in Tables 2 and E4.

\section{Overall Survival}

Figure 1 shows Kaplan-Meier survival curves and landmark analyses. Thirty-day mortality rates were $2.9 \%$ for aneurysm, $9.3 \%$ for small root, $11.2 \%$ for other, $14.6 \%$ for endocarditis, and $27.4 \%$ for type A dissection (Table 3). Survival of the standardized Danish general population overlapped the intermediate-term survival for 90day survivors of the elective indications (aneurysm, small root, and other), whereas patients with endocarditis and type A dissection had excess mortality, also for 90-day survivors (Figures 1 and E2). Subgroup-analysis of survival according to sex showed similar trends per indication (Figure E3).

\section{Reinterventions}

Fifty-two patients $(5.2 \%)$ had valve-related reinterventions during follow-up (Figure 2, A), most occurred among 
TABLE 1. Preoperative patient characteristics according to indication for unselected aortic root replacement with the Freestyle bioprosthesis at 6 North-Atlantic centers

\begin{tabular}{|c|c|c|c|c|c|c|c|}
\hline$\%(\mathrm{~N})$ & $\frac{\text { Aneurysm }}{100(410)}$ & $\frac{\text { Small root }}{100(86)}$ & $\begin{array}{c}\text { Other } \\
100(141)\end{array}$ & $\frac{\text { Endocarditis }}{100(276)}$ & $\frac{\text { Type A dissection }}{100(117)}$ & $\frac{\text { All }}{100(1030)}$ & $P$ value \\
\hline \multicolumn{8}{|l|}{ Age, y } \\
\hline Median (IQR) & $67.0(61.0-72.0)$ & $68.0(58.2-73.0)$ & $65(55.2-71.0)$ & $63.0(51.5-71.0)$ & $66.0(60.0-71.0)$ & $66(58.0-71.8)$ & $<.0001$ \\
\hline Range & $22-85$ & $18-84$ & $24-86$ & $14-86$ & $33-82$ & $14-86$ & \\
\hline Age $<60$ y & $22.4(92)$ & $26.7(23)$ & $42.3(60)$ & $42.2(116)$ & $27.4(32)$ & $31.4(323)$ & $<.0001$ \\
\hline Male sex & $72.2(296)$ & $22.1(19)$ & $57.7(82)$ & $81.8(225)$ & $67.5(79)$ & $68.1(701)$ & $<.0001$ \\
\hline Median BMI (IQR) & $26.1(231-28.7)$ & $26.2(23.5-30.5)$ & $25.8(23.2-30.8)$ & $25.5(23.0-29.0)$ & $25.5(23.4-28.0)$ & $25.9(23.13-29.0)$ & \\
\hline BMI according to category & & & & & & & .08 \\
\hline$<20$ & $5.2(21)$ & $5.9(5)$ & $4.4(6)$ & $5.3(14)$ & $6.4(7)$ & $5.3(53)$ & \\
\hline $20-30$ & 77.9 (313) & $65.9(56)$ & $67.2(92)$ & $75.3(198)$ & $78.2(86)$ & $74.7(745)$ & \\
\hline$>30$ & $16.9(68)$ & $28.2(24)$ & $28.5(39)$ & $19.4(51)$ & $15.5(17)$ & $20.0(199)$ & \\
\hline $\begin{array}{l}\text { Median eGFR (IQR), } \\
\mathrm{mL} / \mathrm{min}\end{array}$ & 78 (64.9-97.6) & $71(56.4-85.3)$ & $75.4(61.2-97.1)$ & $77.4(52.7-90.0)$ & $71.8(57.5-82.0)$ & $76(60-90)$ & .0006 \\
\hline Dialysis & $0.2(1)$ & $1.2(1)$ & $0.7(1)$ & $8.1(22)$ & $0.9(1)$ & $2.5(26)$ & $<.0001$ \\
\hline Diabetes mellitus & $5.9(24)$ & $15.1(13)$ & 9.9 (14) & $14.0(38)$ & $3.4(4)$ & $9.1(93)$ & .0002 \\
\hline Insulin-dependent diabetes & $1.5(6)$ & $3.5(3)$ & $2.8(4)$ & $2.6(7)$ & $0.9(1)$ & $2.0(21)$ & .52 \\
\hline Hypertension & $65.0(265)$ & $59.3(51)$ & $63.4(90)$ & $51.9(137)$ & $60.3(70)$ & $60.3(613)$ & $<.0001$ \\
\hline Hypercholesterolemia & $42.8(161)$ & $52.9(45)$ & $48.2(67)$ & $35.4(87)$ & $30.5(32)$ & $41.2(392)$ & .002 \\
\hline Atrial fibrillation & $17.8(73)$ & $14.1(12)$ & $22.9(32)$ & $27.0(70)$ & $16.2(19)$ & 20.4 (206) & .01 \\
\hline Coronary artery disease & $23.3(94)$ & $33.7(29)$ & $29.7(41)$ & $21.7(57)$ & $12.2(14)$ & $23.4(235)$ & .002 \\
\hline Chronic lung disease & $13.3(54)$ & $15.3(13)$ & $11.3(16)$ & $9.6(26)$ & $14.5(17)$ & $12.3(126)$ & .46 \\
\hline $\begin{array}{l}\text { Previous cerebrovascular } \\
\text { disease }\end{array}$ & $9.0(37)$ & $14.0(12)$ & $14.9(21)$ & $24.3(66)$ & $15.4(18)$ & $15.0(154)$ & $<.0001$ \\
\hline Peripheral vascular disease & $4.6(19)$ & $9.3(8)$ & $6.4(9)$ & $5.2(14)$ & $5.1(6)$ & $5.5(56)$ & .51 \\
\hline Bicuspid valve & 40.9 (167) & $15.1(13)$ & $15.9(22)$ & $14.3(39)$ & $7.7(9)$ & $24.5(250)$ & $<.0001$ \\
\hline Previous cardiac surgery & $9.3(38)$ & $9.3(8)$ & $73.9(105)$ & $68.6(188)$ & $9.5(11)$ & $34.0(350)$ & $<.0001$ \\
\hline Aortic surgery & $8.3(34)$ & $2.4(2)$ & $64.8(92)$ & $64.2(176)$ & $7.8(9)$ & $30.5(313)$ & \\
\hline CABG & $1.2(5)$ & $0.0(0)$ & $10.6(15)$ & $8.5(23)$ & $1.7(2)$ & $4.4(45)$ & \\
\hline Other & $0.2(1)$ & $7.0(6)$ & $7.0(10)$ & $4.4(12)$ & $0.0(0)$ & $2.8(29)$ & \\
\hline Previous endocarditis & $1.7(7)$ & $0.0(0)$ & $14.8(21)$ & $28.2(77)$ & $0.9(1)$ & $10.3(106)$ & $<.0001$ \\
\hline Aortic valve lesion & & & & & & & $<.0001$ \\
\hline $\begin{array}{l}\text { Severe aortic } \\
\text { regurgitation }\end{array}$ & $64.4(264)$ & $10.5(9)$ & $33.1(47)$ & $33.5(92)$ & $50.4(59)$ & $45.7(471)$ & \\
\hline Severe aortic stenosis & $17.6(72)$ & $74.4(64)$ & $43.7(62)$ & $14.5(40)$ & $2.6(3)$ & $23.4(241)$ & \\
\hline Mixed lesion & $0.5(2)$ & $5.8(5)$ & $0.0(0)$ & $0.4(1)$ & $0.0(0)$ & $0.8(8)$ & \\
\hline Competent valve & $10.7(44)$ & $3.5(3)$ & $9.9(14)$ & $13.8(38)$ & $18.8(22)$ & $11.7(121)$ & \\
\hline Unreported & $6.8(28)$ & $5.8(5)$ & 13.4 (19) & $37.8(104)$ & $28.2(33)$ & $18.3(189)$ & \\
\hline \multicolumn{8}{|l|}{ LVEF } \\
\hline Median (IQR), \% & $55(47-60)$ & $60(55-65)$ & $55(46-60)$ & $50(45-60)$ & $55(50-60)$ & $55(50-60)$ & $<.0001$ \\
\hline Range & $15-73$ & $25-80$ & $10-70$ & $15-83$ & $25-65$ & $10-83$ & \\
\hline NYHA class & & & & & & & $<.0001$ \\
\hline I & $34.2(127)$ & $13.0(10)$ & $11.5(15)$ & $23.6(41)$ & $31.7(20)$ & $26.1(213)$ & \\
\hline II & 40.4 (150) & $41.6(32)$ & $32.3(42)$ & $20.7(36)$ & $14.3(9)$ & $33.0(269)$ & \\
\hline III-IV & $25.3(94)$ & $45.5(35)$ & $56.2(73)$ & $55.7(97)$ & $54.0(34)$ & $40.9(333)$ & \\
\hline Surgical priority & & & & & & & $<.0001$ \\
\hline Elective & $89.8(368)$ & $89.5(77)$ & $58.2(82)$ & $5.5(15)$ & $7.7(9)$ & $53.7(551)$ & \\
\hline $\begin{array}{l}\text { Urgent, emergent, } \\
\text { or salvage }\end{array}$ & $10.2(42)$ & $10.5(9)$ & $41.8(59)$ & 94.5 (258) & $92.3(108)$ & $46.3(476)$ & \\
\hline
\end{tabular}


TABLE 1. Continued

\begin{tabular}{|c|c|c|c|c|c|c|c|}
\hline & Aneurysm & Small root & Other & Endocarditis & Type A dissection & All & \\
\hline$\%(\mathbf{N})$ & $100(410)$ & $100(86)$ & $100(141)$ & $100(276)$ & $100(117)$ & $100(1030)$ & $P$ value \\
\hline Cardiogenic shock & $0.0(0)$ & $0.0(0)$ & $3.5(5)$ & $1.8(5)$ & $10.3(12)$ & $2.1(22)$ & $<.0001$ \\
\hline \multicolumn{8}{|l|}{ EuroSCORE II } \\
\hline Median (IQR), \% & $2.4(1.5-4.2)$ & $3.2(1.9-6.6)$ & $8.4(4.3-16.2)$ & $16.7(10.3-27.8)$ & $5.6(3.5-10.4)$ & $5.2(2.4-13.1)$ & $<.0001$ \\
\hline Range & $1.0-55.8$ & $1.1-48.1$ & $1.0-77.3$ & $1.8-74.2$ & $1.2-59.1$ & $1.0-77.3$ & \\
\hline
\end{tabular}

All data are reported as \% (n) except where otherwise noted. For missing values, see Table E1. IQR, Interquartile range; $B M I$, body mass index; $e G F R$, estimated glomerular filtration rate calculated using the Cockcroft-Gault formula; $C A B G$, coronary artery bypass graft; $L V E F$, left ventricular ejection fraction; NYHA, New York Heart Association functional classification; EuroSCORE, European System for Cardiac Operative Risk Evaluation.

the endocarditis patients. There were $29(2.9 \%)$ reinterventions because of endocarditis including 20 cases with recurrent infection. Thirteen reinterventions $(1.3 \%)$ were because of pseudoaneurysms and $8(0.8 \%)$ were because of structural valve deterioration (all of them with aortic regurgitation). One reintervention $(0.1 \%)$ was because of

TABLE 2. Preoperative characteristics according to indication for unselected aortic root replacement with the Freestyle bioprosthesis at 6 North Atlantic centers

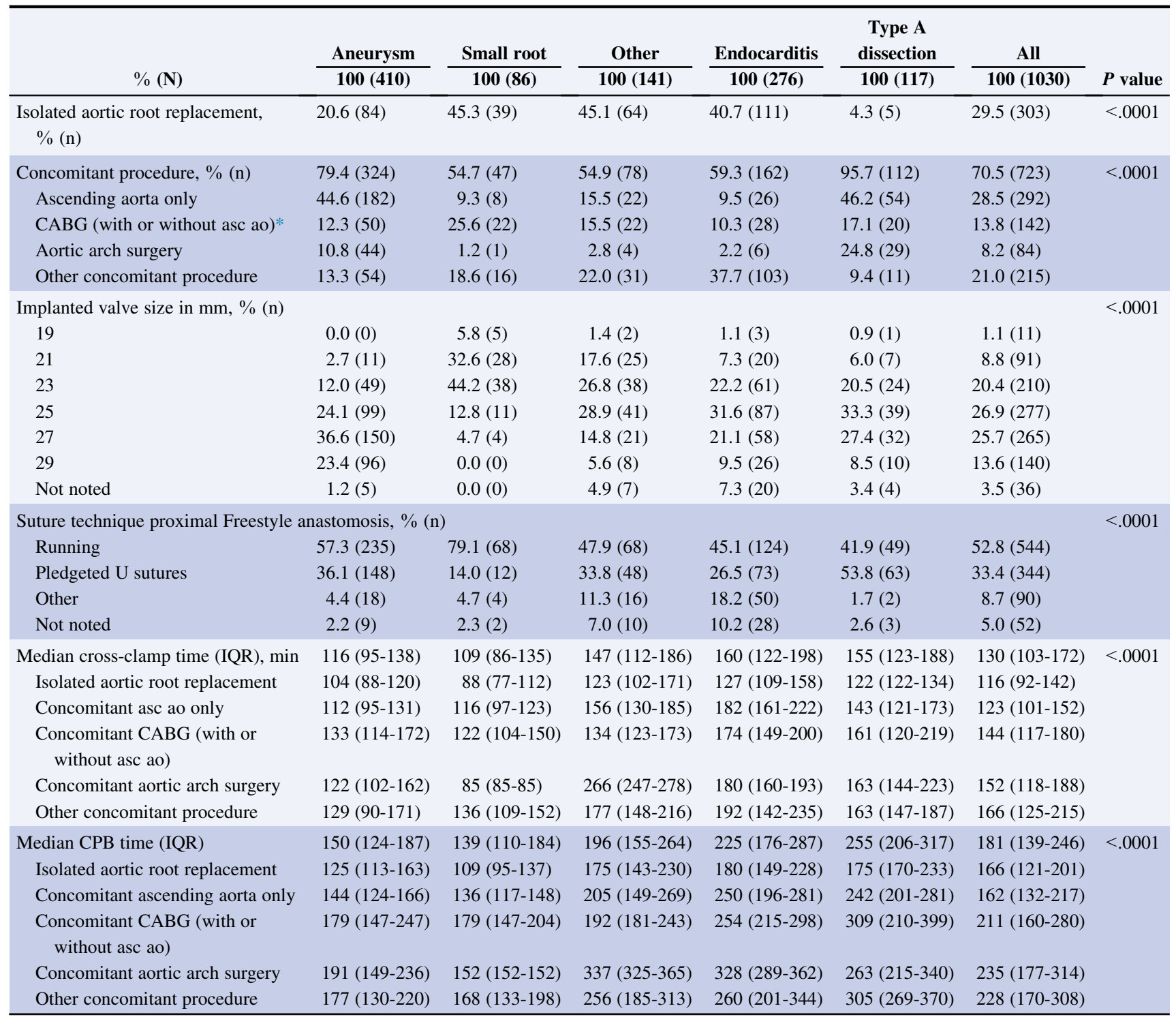

For missing values, see Table $\mathrm{E} 4 . C A B G$, Coronary artery bypass grafting; $a s c$, ascending; $a o$, aorta; $I Q R$, interquartile range; $C P B$, cardiopulmonary bypass. *Including planned and unplanned $\mathrm{CABG}$ at the same occasion. 


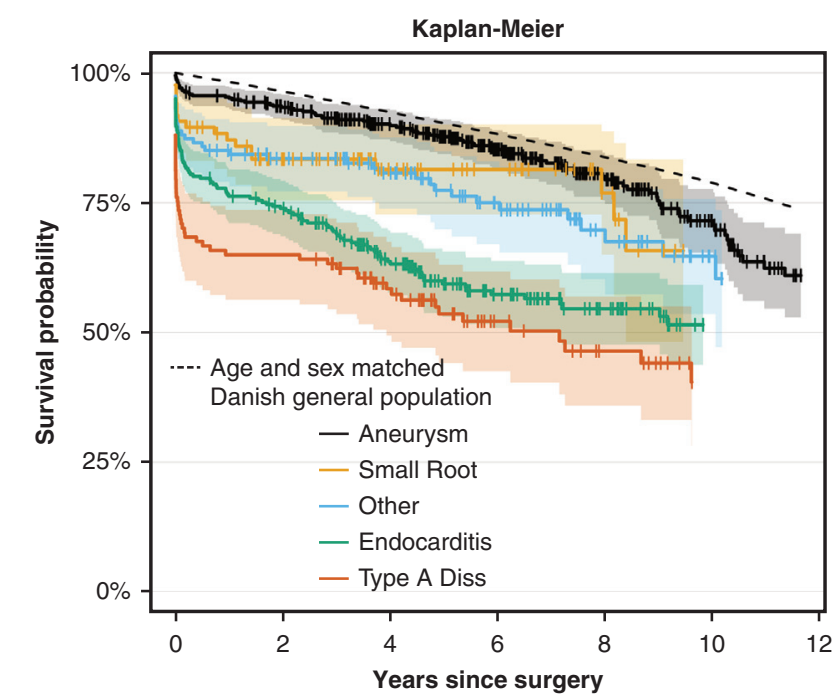

Aneurysm: $410 \quad 387 \quad 366 \quad 341302272217 \quad 175 \quad 137 \quad 102 \quad 81 \quad 50$ Small Root: $86 \quad 71 \quad 61 \quad 52 \quad 38 \quad 33 \quad 29 \quad 24 \quad 16 \quad 10$ Other: $134 \begin{array}{llllllllll}111 & 101 & 97 & 84 & 68 & 55 & 44 & 30 & 24 & 16\end{array}$ Endocarditis: $\begin{array}{llllllllll}261 & 198 & 188 & 165 & 132 & 98 & 77 & 61 & 50 & 37\end{array}$

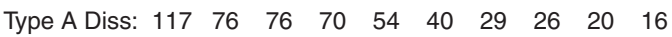

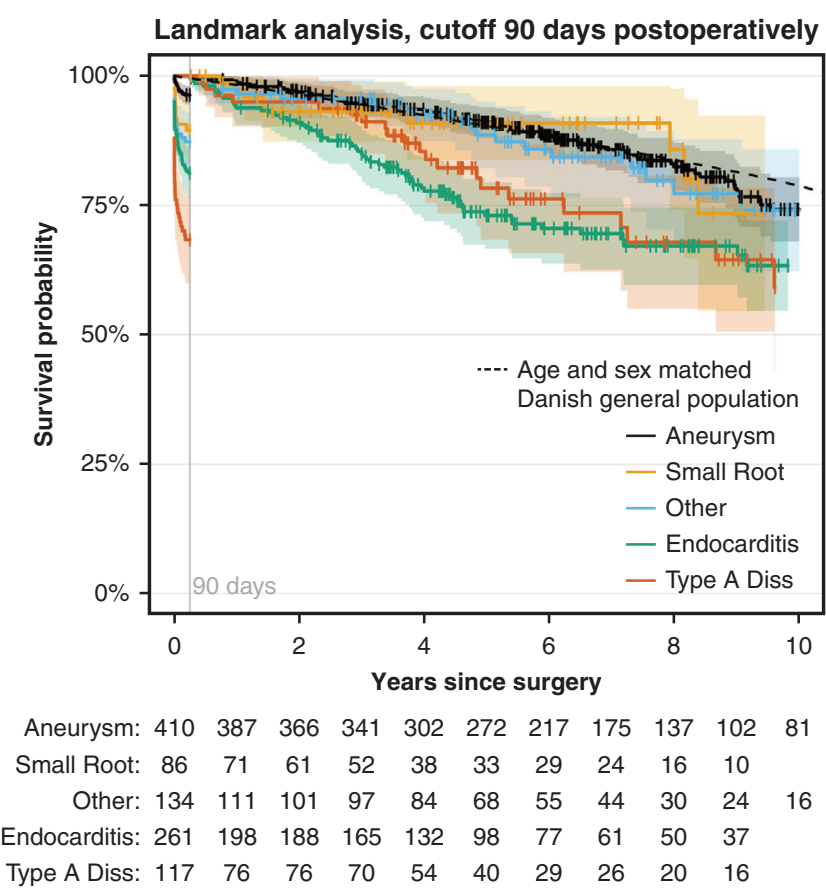

B

\begin{tabular}{|c|c|c|c|c|}
\hline \multirow{6}{*}{ 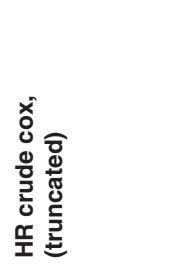 } & & $\begin{array}{l}0-9.61 \text { years } \\
\text { HR }(95 \% \mathrm{Cl})\end{array}$ & $\begin{array}{l}\text { 0-90 days } \\
\text { HR }(95 \% \mathrm{Cl})\end{array}$ & $\begin{array}{c}0.25-9.61 \text { years } \\
\text { HR }(95 \% \mathrm{Cl})\end{array}$ \\
\hline & Aneurysm: & 1.00 & 1.00 & 1.00 \\
\hline & Small Root: & $1.43(0.85-2.38)$ & $2.97(1.30-6.78)$ & $1.03(0.51-2.07)$ \\
\hline & Other: & $1.62(1.08-2.41)$ & 3.69 (1.84-7.39) & $1.09(0.65-1.85)$ \\
\hline & Endocarditis: & $2.86(2.13-3.83)$ & 5.57 (3.12-9.93) & $2.20(1.54-3.15)$ \\
\hline & Type A Dissection: & $3.79(2.69-5.33)$ & $10.52(5.77-19.17)$ & $1.91(1.16-3.14)$ \\
\hline \multirow{5}{*}{ 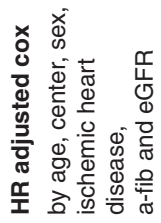 } & Aneurysm: & 1.00 & 1.00 & 1.00 \\
\hline & Small Root: & $1.41 \quad(0.82-2.42)$ & $2.99(1.26-7.10)$ & $0.99(0.47-2.06)$ \\
\hline & Other: & $1.72(1.15-2.58)$ & $4.01 \quad(1.99-8.08)$ & $1.12(0.66-1.91)$ \\
\hline & Endocarditis: & $2.98(2.18-4.06)$ & 5.94 (3.26-10.82) & $2.18(1.49-3.19)$ \\
\hline & Type A Dissection: & $4.05(2.84-5.77)$ & $11.63(6.31-21.44)$ & $1.91(1.15-3.19)$ \\
\hline
\end{tabular}

\section{C}

FIGURE 1. Survival after unselected aortic root replacement with the Freestyle (Medtronic Inc, Minneapolis, Minn) bioprosthesis, according to indication. These 1008 patients underwent aortic root replacement with a stentless xenograft at 6 North Atlantic centers. Survival status follow-up was $100 \%$ complete. Survival was stratified for indication for root replacement; curves are truncated at $10 \%$ remaining at risk in each indication group, vertical ticks represent censor points and the $95 \%$ confidence interval $(C I)$ is visualized as shading. The stapled line represents survival for the age-, sex-, and birth datestandardized Danish general population. A, Kaplan-Meier survival curves. B, Landmark analysis with cutoff at 90 days postoperatively. C, Crude and adjusted hazard ratios (HRs) obtained using Cox proportional hazards regression for overall survival, truncated at 9.61 years where all indications have $10 \%$ of patients remaining at risk, at 90 days and at 0.25-9.61 years, respectively. Diss, Dissection; $a$ - fib, atrial fibrillation; $e G F R$, estimated glomerular filtration rate.

valve thrombosis. Three valve-related interventions were performed as transcatheter valve-in-valve procedures.

Overall freedom from valve-related reinterventions was $95.0(95 \% \mathrm{CI}, 93.6-96.5)$ at 5 years and $94.4 \%(95 \% \mathrm{CI}$, 92.6-96.1) at 8 years. Eighteen patients $(1.8 \%)$ had postoperative coronary revascularizations (Figure $2, B$ ). Nine of these occurred early ( $0-42$ days postoperatively), among patients operated for small root $(n=4)$, aneurysm $(n=3)$, and endocarditis $(\mathrm{n}=2)$. All early revascularizations were in patients with confirmed or suspected proximal coronary lesions. The remaining 9 occurred for all indications in 0.45.8 years postoperatively; the coronary lesions were distal 
TABLE 3. Kaplan-Meier analysis of all-cause death after unselected aortic root replacement with the Freestyle bioprosthesis

\begin{tabular}{|c|c|c|c|c|c|c|c|c|c|c|c|c|}
\hline \multirow[b]{3}{*}{$\%(\mathrm{~N})$} & \multirow{2}{*}{\multicolumn{2}{|c|}{$\frac{\text { Aneurysm }}{100(410)}$}} & \multirow{2}{*}{\multicolumn{2}{|c|}{$\frac{\text { Small root }}{100(86)}$}} & \multirow{2}{*}{\multicolumn{2}{|c|}{$\begin{array}{c}\text { Other } \\
100(142)\end{array}$}} & \multirow{2}{*}{\multicolumn{2}{|c|}{$\frac{\text { Endocarditis }}{100(275)}$}} & \multirow{2}{*}{\multicolumn{2}{|c|}{$\begin{array}{c}\begin{array}{c}\text { Type A } \\
\text { dissection }\end{array} \\
100(117)\end{array}$}} & \multirow{2}{*}{\multicolumn{2}{|c|}{$\frac{\text { All }}{100(1030)}$}} \\
\hline & & & & & & & & & & & & \\
\hline & $\%(\mathbf{n})$ & $95 \% \mathrm{CI}$ & $\%(n)$ & $95 \% \mathrm{CI}$ & $\%($ n) & $95 \% \mathrm{CI}$ & $\%(\mathbf{n})$ & $95 \% \mathrm{CI}$ & $\%(\mathbf{n})$ & $95 \% \mathrm{CI}$ & $\%(\mathbf{n})$ & $95 \% \mathrm{CI}$ \\
\hline \multicolumn{13}{|c|}{ Early mortality, \% (n deaths) } \\
\hline $\begin{array}{l}\text { Periprocedural } \\
\quad(<72 \mathrm{~h})\end{array}$ & $0.7(3)$ & $0.0-1.6$ & $2.3(2)$ & $0.0-5.5$ & $8.2(11)$ & $3.6-12.9$ & $10.3(27)$ & $6.7-14.0$ & $20.5(24)$ & $13.2-27.8$ & $6.6(67)$ & $5.1-8.2$ \\
\hline $30-d$ & $2.9(12)$ & $1.3-4.6$ & $9.3(8)$ & $3.2-15.4$ & $11.2(15)$ & $5.9-16.5$ & $14.6(38)$ & $10.3-18.8$ & $27.4(32)$ & $19.3-35.4$ & 10.4 (105) & $8.5-12.3$ \\
\hline $90-d$ & $3.7(15)$ & $1.8-5.5$ & $10.5(9)$ & $4.0-16.9$ & 12.7 (17) & $7.1-18.3$ & $18.8(49)$ & $14.0-23.5$ & $31.6(37)$ & $23.2-40.0$ & 12.6 (127) & $10.6-14.6$ \\
\hline \multicolumn{13}{|l|}{$\begin{array}{l}\text { Late survival, } \\
\qquad \% \text { (n deaths) }\end{array}$} \\
\hline $1 \mathrm{y}$ & 95.4 (19) & $93.3-97.4$ & $87.1(11)$ & $80.0-94.2$ & $85.1(20)$ & $79.0-91.1$ & $76.2(62)$ & $71.1-81.4$ & $65.0(41)$ & $56.3-73.6$ & $84.8(153)$ & $82.6-87.0$ \\
\hline $3 y$ & $91.3(35)$ & $88.5-94.0$ & 83.4 (14) & $75.4-91.3$ & $83.5(22)$ & $77.2-89.8$ & $69.0(80)$ & $63.4-74.7$ & $62.3(44)$ & 53.6-71.1 & 80.4 (195) & $77.9-82.9$ \\
\hline $5 \mathrm{y}$ & 87.7 (47) & $84.5-91.0$ & $81.4(15)$ & $72.7-90.1$ & $77.4(28)$ & $69.9-84.9$ & $59.3(100)$ & $53.1-65.6$ & $53.6(52)$ & $44.1-63.0$ & 74.4 (242) & 71.6-77.2 \\
\hline $7.5 \mathrm{y}$ & $80.6(64)$ & $76.1-85.1$ & $81.4(15)$ & $72.7-90.1$ & $71.8(32)$ & $63.1-80.6$ & $54.6(106)$ & $47.7-61.4$ & $46.4(56)$ & $35.9-56.9$ & $68.6(273)$ & $65.3-71.8$ \\
\hline $10 \mathrm{y}$ & $71.5(77)$ & $65.4-77.7$ & $65.8(18)$ & $83.3-48.2$ & $64.7(35)$ & $53.6-75.8$ & $51.5(108)$ & $43.8-59.2$ & NA* & - & $61.2(296)$ & $57.1-65.3$ \\
\hline
\end{tabular}

CI, Confidence interval; $N A$, nonapplicable. *Number at risk $<10 \%$ and therefore not reported.

$(\mathrm{n}=2)$, proximal $(\mathrm{n}=5)$, or combined $(\mathrm{n}=2)$. Eight patients had known survival status but unknown revascularization status because of inaccessible records and were lostto-follow-up for this analysis.

\section{Early Complications}

Perioperative myocardial infarction occurred in 11 $(13.3 \%)$ patients with small roots; other groups ranged from $3.2 \%$ to $9.0 \%$ (Table 4 ). Four patients had their prosthesis replaced early because of continued bleeding $(\mathrm{n}=1)$ or early suspicion of recurrent endocarditis $(n=3)$.

\section{DISCUSSION}

In this report we describe the outcomes in to our knowledge, the largest published Freestyle aortic root replacement cohort, so far. It testifies to the wide range of aortic root pathologies for which this stentless bioprosthesis is used. Furthermore, because survival of aneurysm patients was similar to the general population, outcome seems determined by patient, more than by prosthesis, characteristics. A summary of the study is shown Figure 3. Our findings reflect a heterogenous cohort of diverse and high-risk patients, represented by the various indication groups, most of which are characterized by well known risk factors for adverse outcome, including nonelective, reoperative, concomitant, and endocarditis surgery. ${ }^{9-14}$ In previously reported mixed aortic root replacement cohorts, nonelective surgery accounted for $4 \%-28 \%$ of included cases compared with $46 \%$ in the current study, and reoperative surgery accounted for $4 \%-27 \%$ of cases compared with $34 \%$ in our study., ${ }^{2,-12,15-32}$ Also, complex endocarditis was our second most common indication, and $70 \%$ of these patients had PVE. Last, in all groups except aneurysm, the most prevalent New York Heart
Association functional classification was III-IV, which is strongly associated with mortality and morbidity after cardiac surgery. ${ }^{9,14,19}$ The overall high level of disease severity in the current study is further reflected by the high proportion of young patients who received a bioprosthesis. This suggests that the surgeons prioritized operative success, and confidence to the Freestyle as a surgical solution, over long-term durability. A summary of publications for the purpose of comparison of our results with suitable study populations is presented in Table 5., $, 9-12,15-32$

\section{Survival}

Early mortality after aortic root replacement or similar procedures for severe aortic root disease ranges between $1.8 \%$ and $28 \%$ (Table 5), ${ }^{2,9-12,15-32}$ Our data compare well with the literature; early and late mortality varies significantly with indication for surgery, with 30-day mortality ranging from $3 \%$ for aneurysms to $27 \%$ for type A dissections. In all studies, including the present, high rates of mortality occur primarily among patients with type A dissection and those with complex endocarditis. The rather high mortality rate in these groups might be explained by the extended surgical aortic root injury in aortic dissection patients and with invasive root abscess formation or redo setting in patients with endocarditis. The relatively low early mortality rate of our elective aneurysm patients is also in line with established knowledge. . $^{, 11,15,16,18,20-22,33}$ Still, the small root group had a 30-day mortality of $9.3 \%(\mathrm{n}=8)$, which is higher than the $4.4 \%$ reported in a recent meta-analysis of patients with small aortic roots. ${ }^{2}$ Only 1 case was related to an early revascularization, but 4 had perioperative myocardial infarctions. Four of the 8 deceased patients were emergent or urgent cases and the median European System for Cardiac Operative Risk 


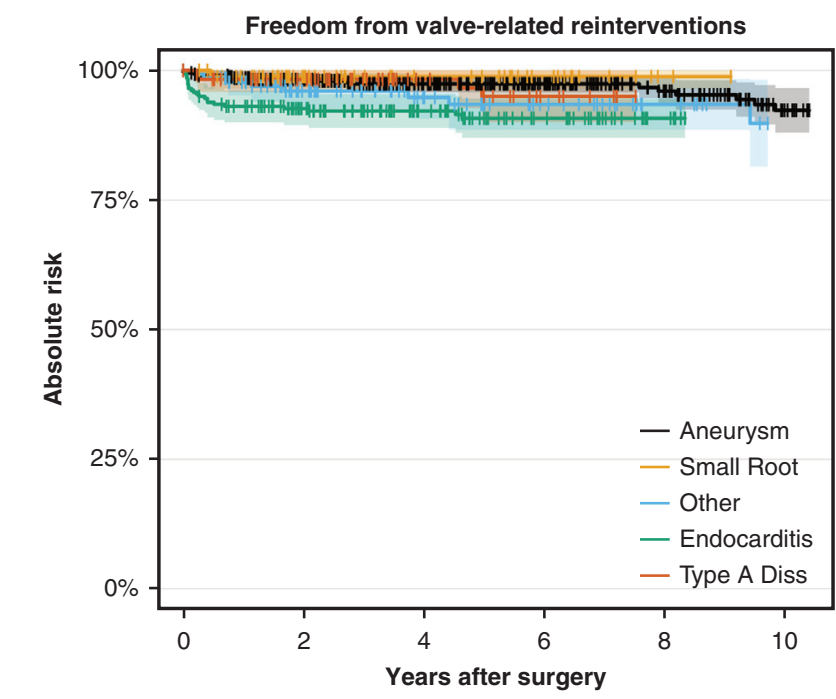

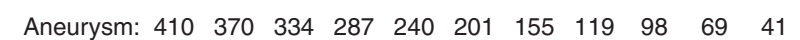

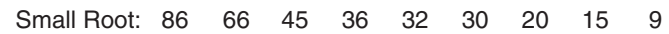

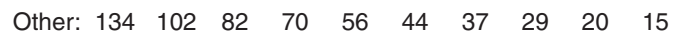

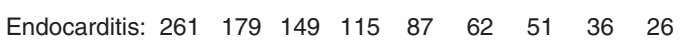

Type A Diss: $117 \quad 70 \quad 62 \quad 47 \quad 32 \quad 26 \quad 20 \quad 11$

A

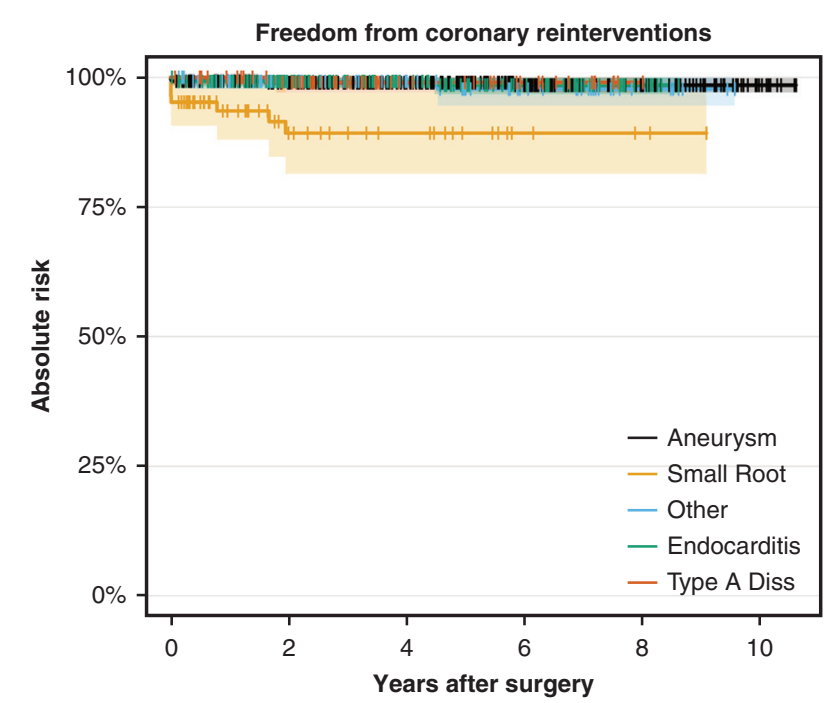

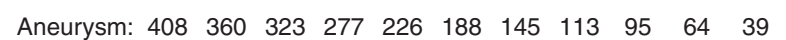

$\begin{array}{llllllllll}\text { Small Root: } & 84 & 46 & 30 & 26 & 23 & 18 & 13 & 13 & 8\end{array}$

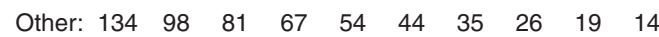

Endocarditis: $\begin{array}{lllllllll}258 & 183 & 148 & 116 & 88 & 64 & 50 & 35 & 24\end{array}$

Type A Diss: $\begin{array}{llllllll}117 & 71 & 62 & 47 & 32 & 29 & 21 & 14\end{array}$

B

\begin{tabular}{|c|c|c|}
\hline \multirow{6}{*}{ 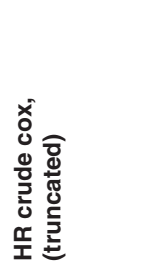 } & & $\begin{array}{l}\text { Valve-related } \\
\text { HR }(95 \% \mathrm{Cl})\end{array}$ \\
\hline & Aneurysm: & 1.00 \\
\hline & Small Root: & $0.48 \quad(0.06-3.71)$ \\
\hline & Other: & $2.14(0.84-5.44)$ \\
\hline & Endocarditis: & 3.88 (1.92-7.87) \\
\hline & Type A Dissection: & $1.89(0.61-5.88)$ \\
\hline \multirow{5}{*}{ 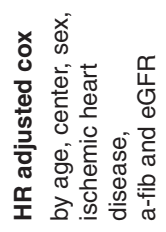 } & Aneurysm: & 1.00 \\
\hline & Small Root: & $0.35(0.04-2.86)$ \\
\hline & Other: & $1.49(0.56-3.95)$ \\
\hline & Endocarditis: & $2.24(1.02-4.92)$ \\
\hline & Type A Dissection: & $1.16(0.36-3.76)$ \\
\hline
\end{tabular}

\begin{tabular}{lll} 
& \multicolumn{1}{c}{$\begin{array}{c}\text { Coronary } \\
\text { HR }\end{array}$} \\
Aneurysm: & 1.00 & \\
Small Root: & 12.01 & $(1.99-72.39)$ \\
Other: & 3.76 & $(0.53-26.72)$ \\
Endocarditis: & 3.27 & $(0.54-19.62)$ \\
Type A Dissection: & $4.40(0.25-30.02)$ \\
& & \\
& & \\
Aneurysm: & 1.00 \\
Small Root: & $5.86(1.44-23.82)$ \\
Other: & $3.39(0.70-16.34)$ \\
Endocarditis: & $1.05(0.28-4.00)$ \\
Type A Dissection: & $0.96(0.12-7.80)$
\end{tabular}

FIGURE 2. Valve-related and coronary reinterventions occurring after unselected aortic root replacement with the Freestyle (Medtronic Inc, Minneapolis, Minn) bioprosthesis, according to indication of index Freestyle implantation. This observational study included 1008 patients from 6 North Atlantic centers. Freedom from reintervention was estimated by Aalen-Johansen analysis with death as competing risk (reported in Figure E4) stratified for indication for root replacement; curves are truncated at $10 \%$ remaining at risk in each indication group, vertical ticks represent censor points, and the $95 \%$ confidence interval $(C I)$ is visualized as shading. A, Freedom from valve-related reinterventions including valve dysfunction, pseudoaneurysms, endocarditis, and thromboses requiring reintervention. B, Freedom from coronary reinterventions including percutaneous interventions and coronary artery bypass grafting. C, Crude and adjusted hazard ratios (HRs) obtained using Cox proportional hazards regression. Adjusted according to age at surgery, center for surgery, ischemic heart disease, atrial fibrillation ( $a-f i b)$, estimated glomerular filtration rate $(e G F R)$, valve size, and suture technique.

Evaluation (EuroSCORE) II of the 8 patients was $10.7 \%$ (range, 2.2\%-48.1\%; only 1 patient had a EuroSCORE II $<7 \%$ ); hence our 30-day mortality rate is not completely unexpected but an over-representation of coronary reimplantation complications as a contributing factor cannot be out-ruled. Intermediate-term survival of patients with elective indications (aneurysm, small root, and other) was comparable or slightly lower than previously reported (Tables 3 and E1)., ${ }^{2,-12,15-32}$ In a landmark analysis with cutoff at 90 days, survival rates up to 10 years for aneurysm, small root, and other were indistinguishable, and furthermore comparable with a reference group from 
TABLE 4. Early complications* after unselected aortic root replacement with the Freestyle bioprosthesis

\begin{tabular}{|c|c|c|c|c|c|c|}
\hline$\%, \mathbf{N}$ & $\frac{\text { Aneurysm }}{100(410)}$ & $\frac{\text { Small root }}{100(86)}$ & $\frac{\text { Other }}{100(142)}$ & $\frac{\text { Endocarditis }}{100(275)}$ & $\frac{\text { Type A dissection }}{100(117)}$ & $\frac{\text { All }}{100(1030)}$ \\
\hline Early reoperation for bleeding or tamponade, $\%$ (n) & $10.7(44)$ & $2.3(2)$ & $16.2(23)$ & $15.6(43)$ & $27.4(32)$ & $14.0(144)$ \\
\hline Median ICU stay (IQR), d & $1(1-2)$ & $1(1-3)$ & $2(1-5)$ & $2(1-6)$ & $4(1-8)$ & $1(1-4)$ \\
\hline Missing (n) & 11 & 2 & 7 & 10 & 0 & 30 \\
\hline Perioperative myocardial infarction, $\%(\mathrm{n}) \dagger$ & $3.2(13)$ & $13.3(11)$ & $6.7(9)$ & $3.6(9)$ & $9.0(9)$ & $5.2(51)$ \\
\hline Missing (n) & 7 & 3 & 8 & 23 & 17 & 58 \\
\hline Postoperative cerebrovascular event, \% (n) & $5.2(21)$ & $3.7(3)$ & $6.0(8)$ & $10.2(26)$ & $22.4(22)$ & $8.2(80)$ \\
\hline Missing (n) & 6 & 4 & 8 & 21 & 19 & 58 \\
\hline Permanent pacemaker implantation, \% (n) & $4.7(19)$ & $7.5(6)$ & $19.4(26)$ & $23.6(60)$ & $5.1(5)$ & $12.0(116)$ \\
\hline Missing (n) & 9 & 6 & 8 & 21 & 18 & 62 \\
\hline
\end{tabular}

$I C U$, Intensive care unit; $I Q R$, interquartile range. *Within 30 days from surgery. †VARC-2-criteria. †ॄDefined as all new-onset neurological symptoms, including TIA

the Danish general population. This is contrary to the survival in patients after conventional aortic valve replacement, which have been shown to exhibit a small but significant late excess mortality, especially in this younger age group, compared with the general population. ${ }^{34}$ This is especially reassuring in light of the previously reported high rates of pseudoaneurysm formation. ${ }^{8,35}$ However, our data seem to support previous reports of continued excess mortality for endocarditis patients and implies that this could also apply to patients with type A dissection (Figure 1, B, Table 5, and Figure E2, $F$ and $L) .{ }^{13,36}$ On this note, late survival for type A dissection appears to be lower than previously reported for root-involving type A dissection, but because our patients were 6-9 years older at the time of surgery than the patients in studies representing comparably complex cases (Table 5), the true difference is probably small. Still, it cannot be ruled out that pseudoaneurysm formation and rupture is a possible mechanism for this excess mortality, although an association between pseudoaneurysms and

\section{Survival after aortic root replacement with a stentless xenograft is determined by patient, not prosthesis characteristics}

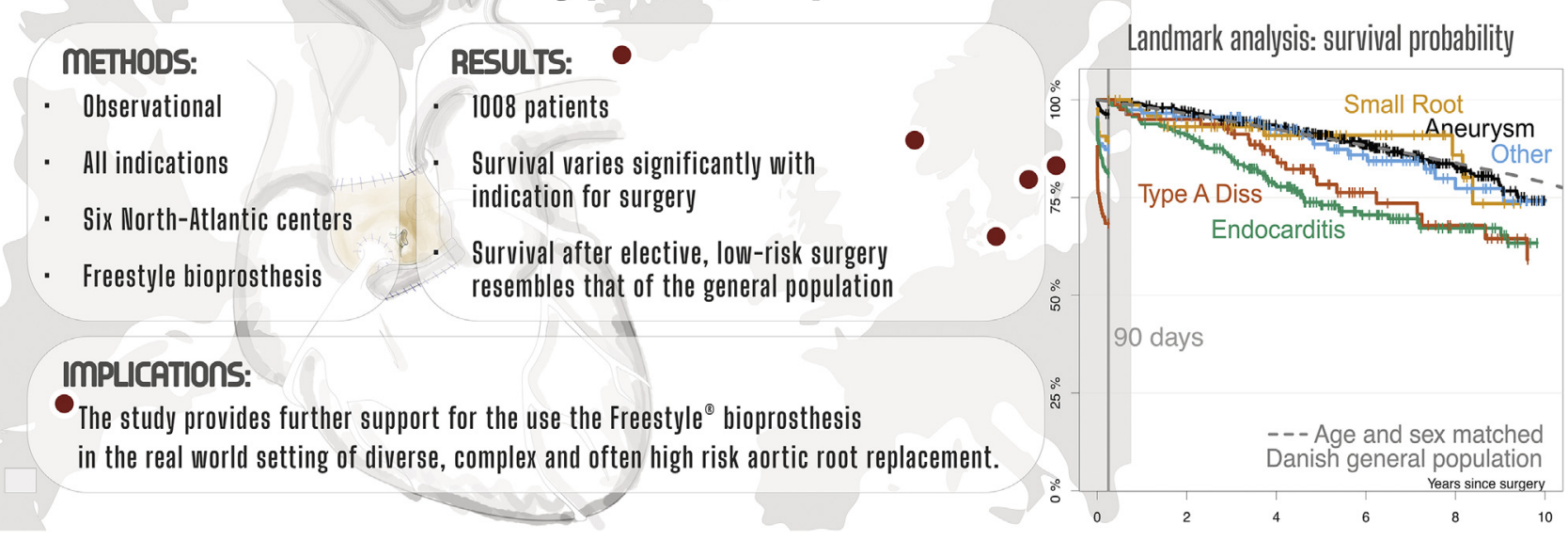

FIGURE 3. Study summary. This was a retrospective, observational North Atlantic multicenter study of survival and reinterventions after aortic root replacement with the stentless xenograft Freestyle (Medtronic Inc, Minneapolis, Minn) bioprosthesis. It included 1008 unselected patients from Copenhagen, Stockholm, Bergen, Montreal, Linköping, and Reykjavik. Results were stratified for the elective indications aneurysm, small root and other and emergent indications, complex endocarditis, and Stanford type A aortic dissection requiring root replacement. In this study survival differed significantly in between indications. Early mortality was high for acknowledged high-risk cases. For 90-day survivors, survival after elective indications resembled that of the sex- and age-standardized Danish general population, whereas those with type A dissection and endocarditis had continued excess mortality. Thus, prosthesis characteristics allow intermediate-term survival corresponding to the background population, and outcome after aortic root replacement with the Medtronic xenograft Freestyle bioprosthesis is determined by patient—rather than by prosthesis—characteristics. It is therefore useful, safe, and durable in the intermediate term in low-risk as well as complex and high-risk surgery. Type A Diss, Type A aortic dissection. 
TABLE 5. Excerpts from publications on ARR with specified indications and procedures: survival and reinterventions

\begin{tabular}{|c|c|c|c|c|c|c|c|c|c|c|c|c|c|c|c|c|}
\hline \multirow{2}{*}{$\begin{array}{c}\text { First } \\
\text { author }{ }^{\text {reference }}\end{array}$} & \multirow[b]{2}{*}{ Design and contents } & \multirow[b]{2}{*}{$\mathbf{N}^{*}$} & \multirow[b]{2}{*}{ ARR, $\% \dagger$} & \multirow{2}{*}{$\begin{array}{c}\text { Mean } \\
\text { age } \pm \text { SD } \\
\text { or median } \\
(\text { IQR })\end{array}$} & \multirow{2}{*}{$\begin{array}{c}\text { NYHA } \\
\text { class } \\
\text { III-IV, \% }\end{array}$} & \multirow{2}{*}{$\begin{array}{l}\text { Concomitant } \\
\text { CABG, } \%\end{array}$} & \multirow{2}{*}{$\begin{array}{c}\text { Redo, } \\
\%\end{array}$} & \multirow{2}{*}{$\begin{array}{c}\text { Priority, } \\
\%\end{array}$} & \multirow{2}{*}{$\begin{array}{c}\text { Population } \\
\text { specification, } \\
\%\end{array}$} & \multirow{2}{*}{$\begin{array}{c}\text { 30-d } \\
\text { mortality, } \\
\%\end{array}$} & \multicolumn{3}{|c|}{ Survival, \% } & \multicolumn{3}{|c|}{$\begin{array}{c}\text { Freedom } \\
\text { from } \\
\text { reinterventions, } \\
\% \\
\end{array}$} \\
\hline & & & & & & & & & & & $5-y$ & Other & $10-y$ & $5-y$ & Other & $10-y$ \\
\hline Zehr $^{15}$ & $\begin{array}{l}\text { Retrospective, composite } \\
\text { ARR vs VSRR for root } \\
\text { aneurysm: subcohort of } \\
\text { ARR }\end{array}$ & 149 & 100 & $54 \pm 16$ & 11 & 13 & 4 & $\begin{array}{c}\text { El: } 96 \\
\text { U:4 }\end{array}$ & - & 4.0 & 93 & - & 79 & 88 & - & 86 \\
\hline Mataraci $^{16}$ & $\begin{array}{l}\text { Retrospective study of all } \\
\text { Bentall de Bono, } \\
\text { indication } 93 \% \text { aneurysm }\end{array}$ & 254 & 100 & $48 \pm 15$ & 34 & 15 & 7 & $\begin{array}{c}\text { El: } 91 \\
\text { U: } 9\end{array}$ & $\begin{array}{l}\text { Hypoth } \\
\text { cardiac } \\
\text { arrest: } 21 \\
\text { A-diss: } 20\end{array}$ & 11.8 & - & - & 84 & 95 & - & $93 \ddagger$ \\
\hline $\begin{array}{l}\text { Doty }^{33} / \\
\text { Bach }^{17}\end{array}$ & $\begin{array}{l}\text { Prospective, Freestyle in ao } \\
\text { valve lesions, subcohort } \\
\text { of full roots (early results, } \\
\text { here in bold, were } \\
\text { reported by Doty and } \\
\text { colleagues) }\end{array}$ & 178 & 100 & $70 \pm 8$ & 73/79 & & NA & & $\begin{array}{l}\text { AS: } 38 \\
\text { Mix: } 43 \\
\text { AR: } 18\end{array}$ & 7.1 & 73 & - & 47 & 98 & - & 92 \\
\hline Byrne $^{18}$ & $\begin{array}{l}\text { Observational, all elective } \\
\text { ARR to compare bio vs } \\
\text { mech }\end{array}$ & 221 & 96 & 53 & 30 & 24 & 13 & El: 100 & $\begin{array}{l}\text { Arch: } 7 \\
\text { A-diss: } 0 \\
\text { IE: } 0 \text { ( } 3.6 \\
\text { "cold" IE) }\end{array}$ & $\begin{array}{r}1.8 \text { (in-hospital } \\
\text { mortality) }\end{array}$ & 91 & - & - & "Low" & - & - \\
\hline Kuwaki $^{19}$ & $\begin{array}{l}\text { Observational, AVR with or } \\
\text { without CABG to } \\
\text { evaluate STS and risk } \\
\text { factors }\end{array}$ & 209 & 0 & $69 \pm 9$ & 53 & 33 & 0 & - & - & 3.8 & 88.6 & - & - & - & - & - \\
\hline Harky ${ }^{2}$ & $\begin{array}{l}\text { Meta-analysis of } 7 \\
\text { observational studies of } \\
\text { stented vs stentless AVR } \\
\text { in the small root }\end{array}$ & 965 & 0 & 75 vs 72 & 56 vs 80 & 27 vs 18 & 0 & & $\begin{array}{r}\text { EScII } 2.1 \\
\text { vs } 2.5\end{array}$ & 5.3 vs 4.4 & 89 vs 80 & - & - & - & - & - \\
\hline Ennker $^{20}$ & $\begin{array}{l}\text { Observational, full root } \\
\text { Freestyle for all } \\
\text { indications. Primarily } \\
\text { aneurysm and small roots }\end{array}$ & 302 & 100 & $72 \pm 9$ & 46 & 23 & 4 & Em: 2 & $\begin{array}{c}\text { Ascending } \\
\text { ao surgery: } \\
31 \\
\text { IE: } 1\end{array}$ & 5.0 & 74 & $9-y: 53$ & - & 99.2 & - & 93.6 \\
\hline Di Marco ${ }^{9}$ & $\begin{array}{l}\text { Retrospective, all composite } \\
\quad \text { (aneurysm } 62 \% \text { ) }\end{array}$ & 1045 & 100 & $59 \pm 14$ & 34.2 & 11 & 12 & $\begin{array}{c}\text { El: } 89 \\
\text { U/Em: } 11\end{array}$ & $\begin{array}{l}\text { A-diss: } 15.5 \\
\text { IE: } 1.3\end{array}$ & 5.3 & 84 & - & 66 & Ca 96 & 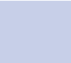 & 94 \\
\hline Mookhoek $^{21}$ & $\begin{array}{l}\text { Meta-analysis of mechanical } \\
\text { Bentall }\end{array}$ & 7629 & 97.8 & 50 & NA & 12 & 16 & Em: 15.8 & $\begin{array}{l}\text { A-diss: } 15.3 \\
\text { IE: } 2\end{array}$ & 5.6 & & OC: 2.02 & & & & \\
\hline Dhurandhar $^{11}$ & $\begin{array}{l}\text { Retrospective multicenter, all } \\
\text { ARR ( } 48 \% \text { aneurysm) }\end{array}$ & 954 & 100 & $56 \pm 15$ & 27 & 21 & 21 & $\begin{array}{c}\text { El: } 75 \\
\text { U/Em/S: } 26\end{array}$ & $\begin{array}{l}\text { A-diss: } 9.5 \\
\text { IE: } 8.5\end{array}$ & $\begin{array}{c}\text { El: } 3.6 \\
\text { U/Em/S: } 12.7 \\
\text { A-diss: } 15.8\end{array}$ & 84 & - & - & - & - & - \\
\hline Schneider ${ }^{22}$ & $\begin{array}{l}\text { Retrospective, all full root } \\
\text { Freestyle }\end{array}$ & 403 & 100 & $62(51-70)$ & 27 & 15 & 27 & $\begin{array}{l}\text { U: } 20 \\
\text { Em: } 8\end{array}$ & $\begin{array}{l}\text { AS: } 35 \\
\text { AR } 45 \\
\text { A-diss: } 8 \\
\text { IE: } 14\end{array}$ & $\begin{array}{l}\text { All: } 7.9 \\
\text { El: } 6.1\end{array}$ & - & $8-y: 59$ & - & - & - & - \\
\hline Berretta $^{10}$ & $\begin{array}{l}\text { Retrospective single-center, } \\
\text { repeat ARR (only } \\
\text { previous ao surgery) vs } \\
\text { primary ARR }\end{array}$ & $\begin{array}{l}180 \text { vs } \\
1087\end{array}$ & 100 & 57 vs 60 & 23 vs 28 & & 13 & $\begin{array}{l}\text { U/Em: } \\
18.9 \text { vs } \\
10.7\end{array}$ & $\begin{array}{l}\text { IE: } 12.2 \\
\text { vs } 0.7 \\
\text { Ao arch: } \\
34 \text { vs } 14.1\end{array}$ & $\begin{array}{l}11.1 \text { vs } 4.1 \\
(\mathrm{OR} 2.9)\end{array}$ & - & - & - & - & - & - \\
\hline El-Hamamsy ${ }^{23}$ & $\begin{array}{l}\text { Retrospective single surgeon, } \\
\text { repeat ARR (only } \\
\text { previous ARR } \\
\text { procedures) }\end{array}$ & 84 & 100 & $38 \pm 15$ & 38 & 12 & 100 & $\mathrm{Em} / \mathrm{U}: 12$ & IE: 15 & 2.4 & 89 & - & 81 & - & - & 97 \\
\hline Esaki $^{24}$ & $\begin{array}{l}\text { Observational, redo ARR (all } \\
\text { previous cardiac/ao } \\
\text { surgery) }\end{array}$ & 280 & 100 & $53 \pm 14$ & & 24 & 100 & Em: 4.6 & $\begin{array}{c}\text { IE: } 18 \\
\text { A-diss: } 2\end{array}$ & 14.3 & 74 & - & - & 95.4 & - & - \\
\hline Di Eusanio ${ }^{25}$ & $\begin{array}{l}\text { Observational, redo ARR (all } \\
\text { previous cardiac/ao } \\
\text { surgery) }\end{array}$ & 111 & 100 & 55 & & & 100 & $\mathrm{Em} / \mathrm{U}: 22$ & & 12.6 & 72 & - & 51 & 92 & - & 86 \\
\hline Leontyev $^{14}$ & $\begin{array}{l}\text { Retrospective, redo AVR with } \\
\text { or without root } \\
\text { replacement }\end{array}$ & 85 vs 69 & 45 & $58 \pm 13$ & 42 & & 100 & $\begin{array}{l}\text { El: } 37 \\
\text { U: } 41 \\
\text { Em: } 21\end{array}$ & $\begin{array}{c}\text { IE: } 27 \\
\text { A-diss: } 2.6\end{array}$ & $\begin{array}{l}\text { ca. } 5.4 \\
\text { both } \\
\text { groups }\end{array}$ & 66 & 8 -y: 68 & - & 87 & 8 -y: 82 & - \\
\hline Jassar $^{27}$ & $\begin{array}{l}\text { Retrospective, ARR for } \\
\text { endocarditis, compare } \\
\text { bio, mech, and homograft }\end{array}$ & 134 & 100 & $58 \pm 15$ & 59 & 12 & 69 & U/Em: 72 & $\begin{array}{l}\text { Root } \\
\text { abscess: } 82 \\
\text { PVE: } 67\end{array}$ & 22 & 59 & - & - & - & - & - \\
\hline Sabik $^{28}$ & $\begin{array}{l}\text { Retrospective, all homograft } \\
\text { replacements because of } \\
\text { prosthetic endocarditis } \\
\text { (Cleveland clinic) }\end{array}$ & 103 & 100 & $57 \pm 15$ & - & - & 100 & - & $\begin{array}{l}\text { Root } \\
\text { abscess: } 78\end{array}$ & 3.9 & 73 & & 56 & - & - & - \\
\hline
\end{tabular}




\begin{tabular}{|c|c|c|c|c|c|c|c|c|c|c|c|c|c|c|c|c|}
\hline \multirow{2}{*}{$\begin{array}{c}\text { First } \\
\text { author }{ }^{\text {reference }}\end{array}$} & \multirow[b]{2}{*}{ Design and contents } & \multirow[b]{2}{*}{$\mathbf{N}^{*}$} & \multirow{2}{*}{ ARR, \%† } & \multirow{2}{*}{$\begin{array}{c}\text { Mean } \\
\text { age } \pm \text { SD } \\
\text { or median } \\
(I Q R)\end{array}$} & \multirow{2}{*}{$\begin{array}{c}\text { NYHA } \\
\text { class } \\
\text { III-IV, \% }\end{array}$} & \multirow{2}{*}{$\begin{array}{l}\text { Concomitant } \\
\text { CABG, } \%\end{array}$} & \multirow{2}{*}{$\begin{array}{c}\text { Redo, } \\
\%\end{array}$} & \multirow{2}{*}{$\begin{array}{c}\text { Priority, } \\
\%\end{array}$} & \multirow{2}{*}{$\begin{array}{c}\text { Population } \\
\text { specification, } \\
\%\end{array}$} & \multirow{2}{*}{$\begin{array}{c}\text { 30-d } \\
\text { mortality, } \\
\%\end{array}$} & \multicolumn{3}{|c|}{ Survival, \% } & \multicolumn{3}{|c|}{$\begin{array}{c}\text { Freedom } \\
\text { from } \\
\text { reinterventions, } \\
\%\end{array}$} \\
\hline & & & & & & & & & & & $5-y$ & Other & $10-y$ & $5-y$ & Other & $10-\mathrm{y}$ \\
\hline Musci $^{12}$ & $\begin{array}{l}\text { Observational single-center, } \\
\text { homograft ARR for } \\
\text { native valve endocarditis } \\
\text { vs PVE }\end{array}$ & 99 vs 122 & 100 & 50 vs 60 & - & - & - & $\begin{array}{c}\text { El: } 6 \text { vs } 9 \\
\text { U: } 70 \text { vs } 75 \\
\text { Em: } 24 \text { vs } 16\end{array}$ & $\begin{array}{c}\text { Root } \\
\text { abscess: } 78 \text { vs } 92\end{array}$ & 16.2 vs 25.4 & 67 vs 48 & - & 47 vs 35 & - & - & - \\
\hline Schneider $^{29}$ & $\begin{array}{l}\text { Retrospective, full root } \\
\text { Freestyle for endocarditis } \\
\text { with extensive root } \\
\text { involvement }\end{array}$ & 54 & 100 & $61 \pm 13$ & - & 18 & 63 & NA & PVE 54 & 11 & $70(\mathrm{CI}, 52-82)$ & - & - & - & - & - \\
\hline Leshnower $^{30}$ & $\begin{array}{l}\text { Review of A-diss with } \\
\text { dissection of the root }\end{array}$ & - & - & - & - & - & - & - & - & $12.3-28$ & 85 & - & 65 & - & - & - \\
\hline Di Eusanio ${ }^{31}$ & $\begin{array}{l}\text { Retrospective registry study } \\
\text { (IRAD), comparing CRR } \\
\text { vs ARR for A diss }\end{array}$ & 699 & 100 & $57 \pm 15$ & 33 Shock & - & 14 & - & Mix VSRR/ARR & 21.3 & - & $3-y: 92$ & - & - & $3-y: 99$ & - \\
\hline Castrovinci $^{32}$ & $\begin{array}{l}\text { Retrospective single-centre, } \\
\text { comparing CRR vs ARR } \\
\text { in A-diss }\end{array}$ & 119 & 100 & $60 \pm 11$ & NA & 8 & 7 & - & Ao. arch: 26 & 21 & 71 & 7-y:63 & - & Prox: 96 & - & - \\
\hline
\end{tabular}

The table contains a selection of publications regarding ao root replacement, or alternative procedures to treat similar pathology. The table illustrates the differences in the baseline characteristics, including proportion of surgical priority and redo surgery, as well as the related results. "Small root" indicates 21-mm annulus or prosthetic size. "Repeat ARR" indicates second-time aortic root surgery. $A R R$, Aortic root replacement; $S D$, standard deviation; $I Q R$, interquartile range; $N Y H A$, New York Heart Association; $C A B G$, coronary artery bypass grafting; redo, reoperative cardiac surgery (ie, redo sternotomy and dissection from adherences); VSRR, valve-sparing root replacement; $E l$, elective; $U$, urgent; Hypoth, hypothermic; $A$-diss, type A aortic dissection; NA, Nonapplicable; $A S$, aortic stenosis; $A \mathrm{R}$, aortic regurgitation; bio, bioprosthetic; mech, mechanical prosthesis; IE, infective endocarditis; AVR, aortic valve replacement; STS, The Society of Thoracic Surgeons; EScII, European System for Cardiac Operative Risk Evaluation II; Em, emergent; ca, circa; $L O C$, linearized occurrence rates; $S$, salvage; Ao, aortic; PVE, prosthetic valve endocarditis; $C I, 95 \%$ confidence interval; IRAD, The International Registry of Acute Aortic Dissection; $C R R$, conservative root management; Prox, proximal (reoperations). *The number of patients on which the following numbers are based might be a subgroup of ARR in a study containing also other procedures. If the included number (and associated results) includes any of these other procedures it is reflected in the proportion of ARR, presented in the following column. †Percentage of the patients represented under " $\mathrm{N}$ " and the reported results - if the cited study contained subgroups that were not relevant and results were reported separately, only ARR cases are included in the table. $\ddagger$ Composite end point with survival. ${ }^{\S}$ For hospital survivors.

indication for Freestyle implantation has not been identified. ${ }^{8}$ A subgroup analysis showed no marked difference between sexes but was underpowered to refute such a difference with certainty.

\section{Reinterventions}

Reintervention rates compare well with previous reports of aortic root replacement for similar indications, regardless of the type of prosthesis used (Table 5). Most of the valverelated reinterventions were because of recurrent endocarditis in the group of endocarditis, again likely reflecting the underlying pathophysiology and comorbidity rather than the choice of prosthesis. Overall freedom from valve-related reintervention during the first 8 years was generally high $(94.4 \%)$. Reinterventions because of structural valve deterioration were rare. Coronary reinterventions primarily occurred among small root patients, who had a 5-year freedom of $90 \%$ (Figure 2, B). Of note, 4 of 7 revascularizations in this group were perioperative and represented 4 of the 7 early revascularizations in the entire study unit. Thus, the small root appears particularly prone to coronary reimplantation complications such as, for example, a kink of the proximal coronary artery, but all early revascularizations must be considered likely complications to coronary artery reimplantation. Even so, all but 1 of the four small root patients and 2 of the 7 patients in all, survived this complication. In all, the authors consider the perioperative risk of kink or other ostial obstruction in relation to aortic root replacement admissible, but the results do underline the importance of coronary positioning when reimplanting the coronary buttons, especially under the narrow conditions seen, for example, in the small root setting. Most of the late coronary lesions were proximal and might represent a complication to the coronary reimplantation.

\section{Early Complications}

Overall complication frequencies are shown in Table 4; they reflect patient characteristics, disease severity, and surgical complexity. The rate of most early complications, including reoperation for bleeding or tamponade, was comparable with previous reports. ${ }^{2,9-11,14-16,18,19,21-24,26-29,31,32,37}$ However, the number of cerebrovascular events in the type A dissection and endocarditis groups were $22.4 \%$ and $10.2 \%$, respectively, compared with up to $10 \%$ observed in other studies of these indications. ${ }^{27,31,32}$ Some studies included only permanent stroke whereas others did not specify inclusion (eg, transient ischemic attacks or stroke without sequelae). The current study included all cerebrovascular events whether they were due to the underlying disease, or real intra- or postoperative events, perhaps explaining the higher rate. The high rate of perioperative myocardial 
infarction $(13.3 \% ; \mathrm{n}=11)$ appears less surprising when the high proportion of coronary artery disease within the small root group $(33.7 \%)$ is considered, corroborated by the need for concomitant coronary artery bypass grafting $(25.6 \%)$ and later increased risk of revascularization (hazard ratio, $12.01 ; 95 \%$ CI, 1.99-72.39). However, the perioperative myocardial infarction and the late revascularizations might represent a particular, technical difficulty of coronary reimplantation among the small root patients.

\section{Strengths and Limitations}

The multicenter design, large study population, and complete follow-up were strengths of the study. Although our study was limited by lack of cause of death, the comparison of the survival of our cohort with that of the standardized general population allows interpretation of the prosthesis implantation's influence on mortality. The main limitations, additional to those inherent to the retrospective study design, included the lack of detailed serial follow-up echocardiographic data. This prohibited estimation of biological valve failure according to the guideline of the 2017 European Association of Percutaneous Cardiovascular Interventions/ European Society of Cardiology/European Association for Cardio-Thoracic Surgery consensus report because of the inability to identify structural valve deterioration not causing reintervention. ${ }^{38}$ Furthermore, proper evaluation of prosthesis-patient mismatch was not possible, information on functional status and quality of life was sparse, and duration of follow-up was limited.

\section{CONCLUSIONS}

In this study of more than 1000 unselected Freestyle full aortic root implantations in patients from 6 small- to medium-sized and comparable centers, survival was equal to that of previous reports of similar cohorts of aortic root procedures, and for elective indications also for that of the general population.

Considering the indications for Freestyle aortic root replacement and the known risk factors for death, the high early mortality rate in high-risk cases might be acceptable. Intermediate-term reintervention rates (valve and coronary) were low and primarily because of recurrent endocarditis. In conclusion, the present intermediate-term study provides further support for the use of the Freestyle full root bioprosthesis in the real-world setting of diverse, complex, and often high-risk aortic root replacement, and suggests that outcome is determined by patient and disease, rather than by prosthesis, characteristics.

\section{Conflict of Interest Statement}

The authors reported no conflicts of interest.

The Journal policy requires editors and reviewers to disclose conflicts of interest and to decline handling or reviewing manuscripts for which they may have a conflict of interest. The editors and reviewers of this article have no conflicts of interest.

The authors thank Jørgen Brekke Vennemo for his valuable contributions in the acquisition of data.

\section{References}

1. Erbel R, Aboyans V, Boileau C, Bossone E, Bartolomeo RD, Eggebrecht H, et al. 2014 ESC guidelines on the diagnosis and treatment of aortic diseases: document covering acute and chronic aortic diseases of the thoracic and abdominal aorta of the adult. The task force for the diagnosis and treatment of aortic diseases of the European Society of Cardiology (ESC). Eur Heart J. 2014;35:2873-926.

2. Harky A, Wong CHM, Hof A, Froghi S, Ahmad MU, Howard C, et al. Stented versus stentless aortic valve replacement in patients with small aortic root: a systematic review and meta-analysis. Innovations (Phila). 2018;13:404-16.

3. Habib G, Lancellotti P, Antunes MJ, Bongiorni MG, Casalta JP, Del Zotti F, et al. 2015 ESC guidelines for the management of infective endocarditis: The task force for the management of infective endocarditis of the European Society of Cardiology (ESC). Endorsed by: European Association for Cardio-Thoracic Surgery (EACTS), the European Association of Nuclear Medicine (EANM). Eur Heart J. 2015;36:3075-128.

4. Bach DS, Kon ND. Long-term clinical outcomes 15 years after aortic valve replacement with the Freestyle stentless aortic bioprosthesis. Ann Thorac Surg. 2014;97:544-51.

5. El-Hamamsy I, Clark L, Stevens LM, Sarang Z, Melina G, Takkenberg JJ, et al. Late outcomes following Freestyle versus Homograft aortic root replacement. J Am Coll Cardiol. 2010;55:368-76.

6. Melina G, De Robertis F, Gaer JA, Angeloni E, El-Hamamsy I, Bahrami T, et al. Long-term survival after xenograft versus homograft aortic root replacement: results from a prospective randomized trial. J Thorac Cardiovasc Surg. October 4, 2019 [Epub ahead of print].

7. Kappetein AP, Head SJ, Genereux P, Piazza N, van Mieghem NM, Blackstone EH, et al. Updated standardized endpoint definitions for transcatheter aortic valve implantation: the Valve Academic Research Consortium-2 consensus document. J Thorac Cardiovasc Surg. 2013;145:6-23.

8. Dagnegård HH, Sigvardsen PE, Ihlemann N, Kofoed KF, El-Hamamsy I, Bekke K, et al. Structural abnormalities after aortic root replacement with stentless xenograft. J Thorac Cardiovasc Surg. May 12, 2021 [Epub ahead of print].

9. Di Marco L, Pacini D, Pantaleo A, Leone A, Barberio G, Marinelli G, et al. Composite valve graft implantation for the treatment of aortic valve and root disease: results in 1045 patients. J Thorac Cardiovasc Surg. 2016;152:1041-8.e1.

10. Berretta P, Di Marco L, Pacini D, Cefarelli M, Alfonsi J, Castrovinci S, et al. Reoperations versus primary operation on the aortic root: a propensity score analysis. Eur J Cardiothorac Surg. 2017;51:322-8.

11. Dhurandhar V, Parikh R, Saxena A, Vallely MP, Wilson MK, Black DA, et al. The aortic root replacement procedure: 12-year experience from the Australian and New Zealand Society of Cardiac and Thoracic Surgeons database. Heart Lung Circ. 2016;25:1245-51.

12. Musci M, Weng Y, Hubler M, Chavez T, Qedra N, Kosky S, et al. Predictors of early mortality in patients with active infective native or prosthetic aortic root endocarditis undergoing homograft aortic root replacement. Clin Res Cardiol. 2009;98:443-50.

13. Ostergaard L, Valeur N, Ihlemann N, Bundgaard H, Gislason G, TorpPedersen $\mathrm{C}$, et al. Incidence of infective endocarditis among patients considered at high risk. Eur Heart J. 2018;39:623-9.

14. Leontyev S, Borger MA, Modi P, Lehmann S, Seeburger J, Walther T, et al. Redo aortic valve surgery: influence of prosthetic valve endocarditis on outcomes. $J$ Thorac Cardiovasc Surg. 2011;142:99-105.

15. Zehr KJ, Orszulak TA, Mullany CJ, Matloobi A, Daly RC, Dearani JA, et al. Surgery for aneurysms of the aortic root: a 30-year experience. Circulation. 2004; 110:1364-71.

16. Mataraci I, Polat A, Kiran B, Caliskan A, Tuncer A, Erentug V, et al. Long-term results of aortic root replacement: 15 years' experience. Ann Thorac Surg. 2009; $87: 1783-8$.

17. Bach DS, Kon ND, Dumesnil JG, Sintek CF, Doty DB. Ten-year outcome after aortic valve replacement with the Freestyle stentless bioprosthesis. Ann Thorac Surg. 2005;80:480-6.

18. Byrne JG, Gudbjartsson T, Karavas AN, Mihaljevic T, Phillips BJ, Aranki SF, et al. Biological vs. mechanical aortic root replacement. Eur J Cardiothorac Surg. 2003;23:305-10. 
19. Kuwaki K, Amano A, Inaba H, Yamamoto T, Matsumura T, Dohi S, et al. Predictors of early and mid-term results in contemporary aortic valve replacement for aortic stenosis. J Card Surg. 2012;27:139-45.

20. Ennker IC, Albert A, Dalladaku F, Rosendahl U, Ennker J, Florath I. Midterm outcome after aortic root replacement with stentless porcine bioprostheses. Eur J Cardiothorac Surg. 2011;40:429-34.

21. Mookhoek A, Korteland NM, Arabkhani B, Di Centa I, Lansac E, Bekkers JA, et al. Bentall procedure: a systematic review and meta-analysis. Ann Thorac Surg. 2016;101:1684-9.

22. Schneider AW, Putter H, Hazekamp MG, Holman ER, Bruggemans EF, Versteegh MIM, et al. Twenty-year experience with stentless biological aortic valve and root replacement: informing patients of risks and benefits. Eur J Cardiothorac Surg. 2018;53:1272-8.

23. El-Hamamsy I, Ibrahim M, Stevens LM, Witzke H, Clark L, Yacoub MH. Early and long-term results of reoperative total aortic root replacement with reimplantation of the coronary arteries. J Thorac Cardiovasc Surg. 2011;142: 1473-7.

24. Esaki J, Leshnower BG, Binongo JN, Lasanajak Y, McPherson L, Thourani VH, et al. Reoperative aortic root replacement: outcome in a contemporary series. $J$ Thorac Cardiovasc Surg. 2017;154:800-8.e3.

25. Di Eusanio M, Berretta P, Cefarelli M, Folesani G, Petridis FD, Di Marco L, et al. Reoperative aortic root replacement: short- and long-term outcomes in 111 patients [in Italian]. G Ital Cardiol (Rome). 2012;13:745-50.

26. Leontyev S, Borger MA, Davierwala P, Walther T, Lehmann S, Kempfert J, et al. Redo aortic valve surgery: early and late outcomes. Ann Thorac Surg. 2011;91: 1120-6.

27. Jassar AS, Bavaria JE, Szeto WY, Moeller PJ, Maniaci J, Milewski RK, et al Graft selection for aortic root replacement in complex active endocarditis: does it matter? Ann Thorac Surg. 2012;93:480-7.

28. Sabik JF, Lytle BW, Blackstone EH, Marullo AG, Pettersson GB, Cosgrove DM. Aortic root replacement with cryopreserved allograft for prosthetic valve endocarditis. Ann Thorac Surg. 2002;74:650-9; discussion: 659.

29. Schneider AW, Hazekamp MG, Versteegh MI, Bruggemans EF, Holman ER, Klautz RJ, et al. Stentless bioprostheses: a versatile and durable solution in extensive aortic valve endocarditis. Eur J Cardiothorac Surg. 2016;49: 1699-704.
30. Leshnower BG, Chen EP. When and how to replace the aortic root in type A aortic dissection. Ann Cardiothorac Surg. 2016;5:377-82.

31. Di Eusanio M, Trimarchi S, Peterson MD, Myrmel T, Hughes GC, Korach A, et al. Root replacement surgery versus more conservative management during type A acute aortic dissection repair. Ann Thorac Surg. 2014;98:2078-84.

32. Castrovinci S, Pacini D, Di Marco L, Berretta P, Cefarelli M, Murana G, et al. Surgical management of aortic root in type A acute aortic dissection: a propensity-score analysis. Eur J Cardiothorac Surg. 2016;50:223-9.

33. Doty DB, Cafferty A, Cartier P, Huysmans HA, Kon ND, Krause AH, et al. Aortic valve replacement with Medtronic Freestyle bioprosthesis: 5-year results. Semin Thorac Cardiovasc Surg. 1999;11:35-41.

34. Glaser N, Persson M, Jackson V, Holzmann MJ, Franco-Cereceda A, Sartipy U Loss in life expectancy after surgical aortic valve replacement: SWEDEHEART study. J Am Coll Cardiol. 2019;74:26-33.

35. Englum BR, Pavlisko EN, Mack MC, Ganapathi AM, Schechter MA, Hanna JM, et al. Pseudoaneurysm formation after Medtronic Freestyle porcine aortic bioprosthesis implantation: a word of caution. Ann Thorac Surg. 2014; 98:2061-7.

36. Thuny F, Grisoli D, Cautela J, Riberi A, Raoult D, Habib G. Infective endocarditis: prevention, diagnosis, and management. Can J Cardiol. 2014;30:1046-57.

37. Easo J, Weymann A, Holzl P, Horst M, Eichstaedt H, Mashhour A, et al. Hospital results of a single center database for stentless xenograft use in a full root technique in over 970 patients. Sci Rep. 2019;9:4371.

38. Capodanno D, Petronio AS, Prendergast B, Eltchaninoff H, Vahanian A, Modine T, et al. Standardized definitions of structural deterioration and valve failure in assessing long-term durability of transcatheter and surgical aortic bioprosthetic valves: a consensus statement from the European Association of Percutaneous Cardiovascular Interventions (EAPCI) endorsed by the European Society of Cardiology (ESC) and the European Association for Cardio-Thoracic Surgery (EACTS). Eur Heart J. 2017;38: 3382-90.

Key Words: aortic root replacement, full root bioprosthesis, survival, reinterventions, endocarditis, type A dissections 


\section{APPENDIX E1. ETHICAL APPROVAL}

The study was approved by the Ethics Committee, Copenhagen Denmark (H-16047065); the local Ethics Committee, Montreal Heart Institute (2017-2336); the Swedish Ethical Review Authority (2017/1198-31/2); the Norwegian regional committee for ethical medical and health research $(2018 / 1548 / \mathrm{REK}$ vest); and The National Bioethics Committee, Iceland (VSN-10-009-V8-S1).

\section{EARLY COMPLICATIONS}

Early complications were defined as occurring within 30 days from surgery. We included all reoperations within 30 days for which the indication was drainage output, pericardial exudate, or tamponade symptoms.

Perioperative myocardial infarction was defined according to the Valve Academic Research Consortium-2 criteria $^{\mathrm{E} 1}$ :

- New ischemic symptoms (eg, chest pain or shortness of breath), or

- New ischemic signs (eg, ventricular arrhythmias, new or worsening heart failure, new ST-segment changes, hemodynamic instability, new pathological Q-waves in at least 2 contiguous leads, imaging evidence of new loss of viable myocardium, or new wall motion abnormality), and
- Elevated cardiac biomarkers (preferable creatinine kinase myocardial band [CK-MB]) within 72 hours after the index procedure, consisting of at least 1 sample post procedure with a peak value exceeding 15 times the upper reference limit for troponin or 5 times for CK-MB. If cardiac biomarkers are increased at baseline ( $>99$ th percentile), a further increase in at least $50 \%$ post procedure is required and the peak value must exceed the previously stated limit.

If the diagnosis perioperative myocardial infarction was posed clinically, but information was not sufficient to assess the previously listed criteria, the event was included.

A postoperative cerebrovascular event was defined as

- Radiologically verified new cerebral lesion, or

- New neurological symptoms (not recurrence of previous symptoms) to ensure inclusion of all relevant events, also in the absence of the detailed information used in the Valve Academic Research Consortium-2 criteria.

Permanent pacemaker implantation: new implantation of a permanent pacemaker.

\section{E-Reference}

E1. Kappetein AP, Head SJ, Genereux P, Piazza N, van Mieghem NM, Blackstone EH, et al. Updated standardized endpoint definitions for transcatheter aortic valve implantation: the Valve Academic Research Consortium-2 consensus document. J Thorac Cardiovasc Surg. 2013;145:6-23. 


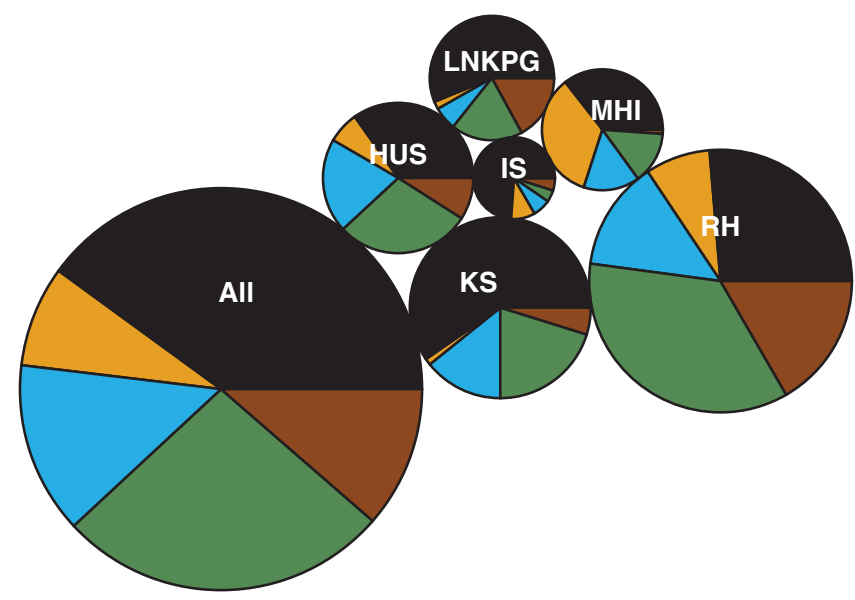

Aneurysm $\square$ Small Root $\square$ Other $\square$ Endocarditis $\square$ Type A Diss

FIGURE E1. Distribution of indications for aortic root replacement with the Freestyle (Medtronic Inc, Minneapolis, Minn) bioprosthesis. All indications were represented at all institutions, but the distribution varied substantially. In the total study population the proportions were: aneurysm (aortic root aneurysm): $39.8 \%(\mathrm{n}=410)$, small root (patients with an aortic valve lesion at risk of prosthesis-patient mismatch): $8.3 \%(\mathrm{n}=86)$, other (technically challenging cases such as redo aortic valve or root, or bailout surgery for aortic root remodeling or reimplantation): $13.8 \%(\mathrm{n}=142)$, complex endocarditis (primarily prosthetic valve endocarditis or aortic root abscess) $26.7 \%(\mathrm{n}=275)$, and Stanford type A aortic dissection (type A Diss), requiring root replacement (eg, because of dissection involving the coronary or reaching the aortic valve): $11.4 \%(\mathrm{n}=117)$. LNKPG, Linköping University Hospital; HUS, Haukeland University Hospital; IS, Landspítali University Hospital of Iceland; $M H I$, Montreal Heart Institute; KS, Karolinska University Hospital; RH, Rigshospitalet, University Hospital of Copenhagen. 


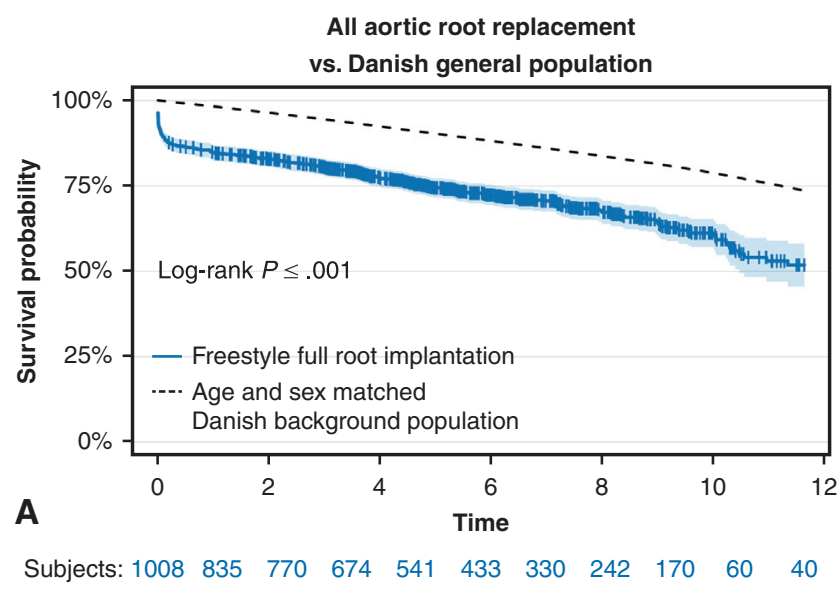

Aortic root replacement for

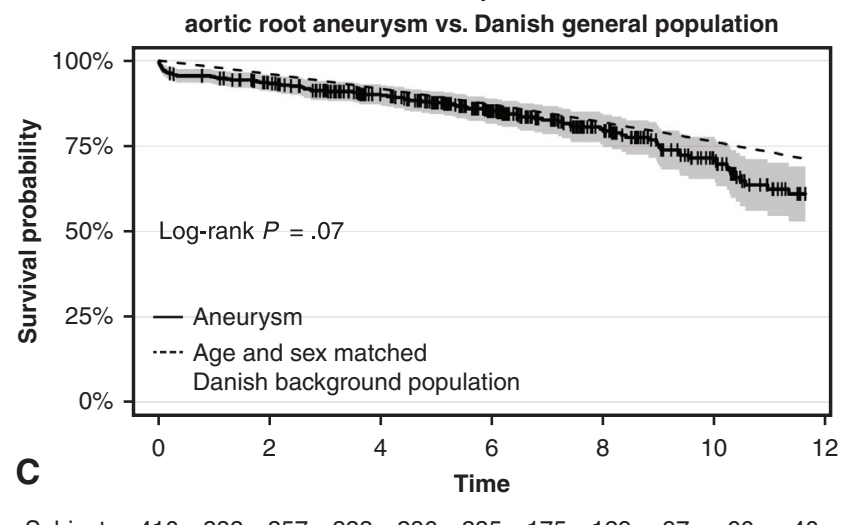

Aortic root replacement for

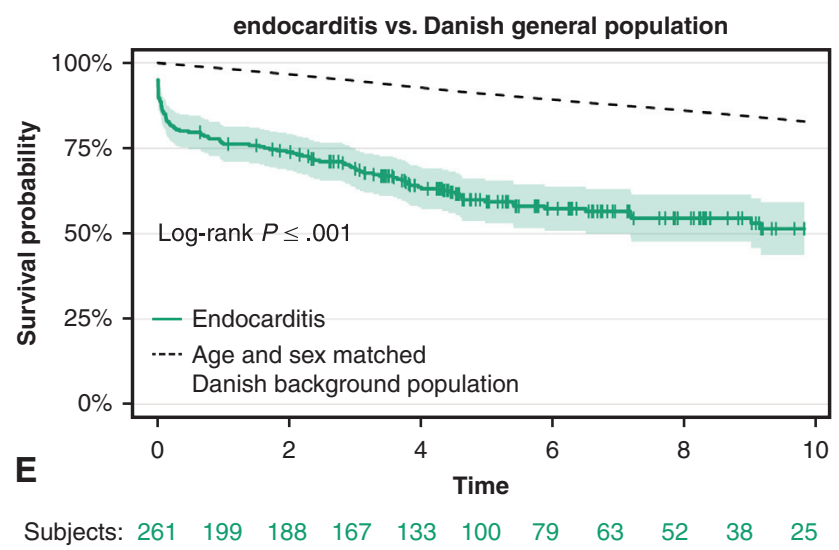

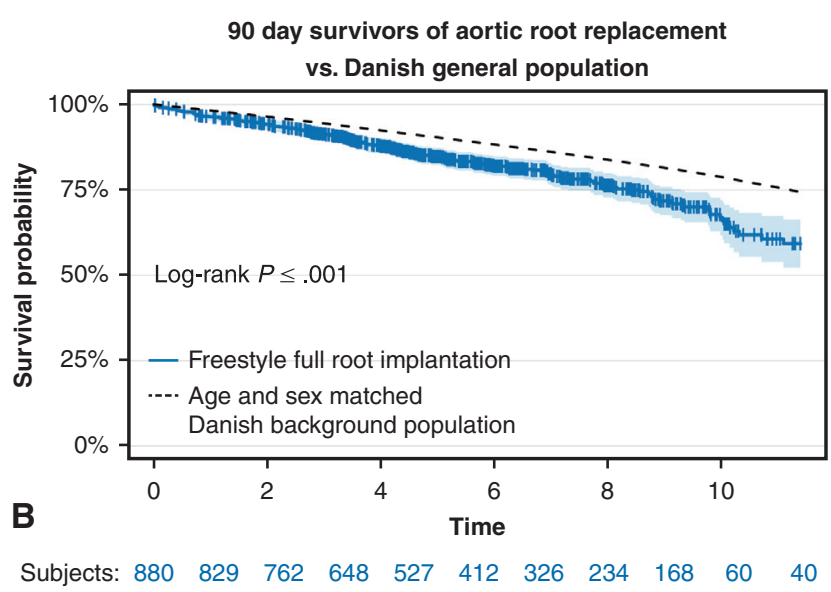

FIGURE E2. All-cause survival for all and for 90-day survivors after aortic root replacement (ARR) with the Freestyle (Medtronic Inc, Minneapolis, Minn) bioprosthesis, compared with the Danish general population. Overall (A and B) and per indication: aneurysm (C and D), small root (E and F), other (G and $\mathrm{H}$ ), endocarditis (I and J), and type A dissection (K and L). Shading indicates $95 \%$ confidence interval. Curves are truncated when $10 \%$ of the population remains at risk, vertical ticks represent censor points. Data for the general population were obtained from the publicly available Human Mortality Database (www.mortality.org), and standardized according to sex and age at year of surgery. 
Aortic root replacement for small root vs. Danish general population

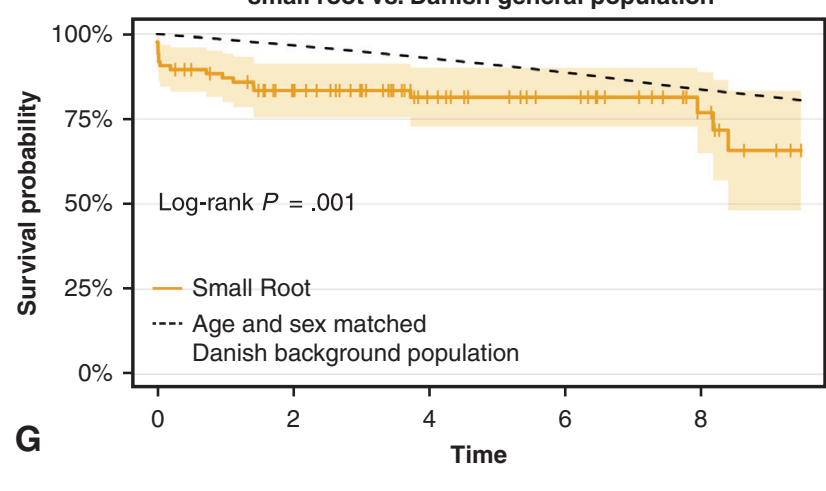

Aortic root replacement for other vs. Danish general population

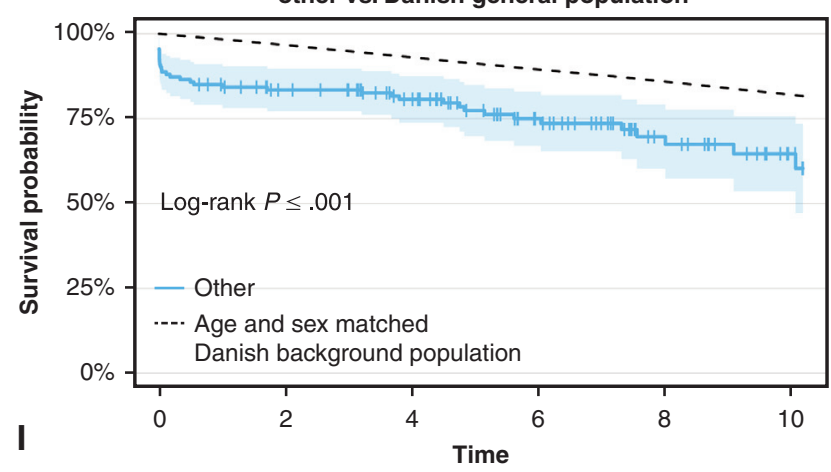

Subjects: $\begin{array}{lllllllllll}134 & 110 & 101 & 97 & 82 & 68 & 52 & 43 & 30 & 23 & 12\end{array}$

Aortic root replacement for Type A aortic Dissection vs. Danish general population

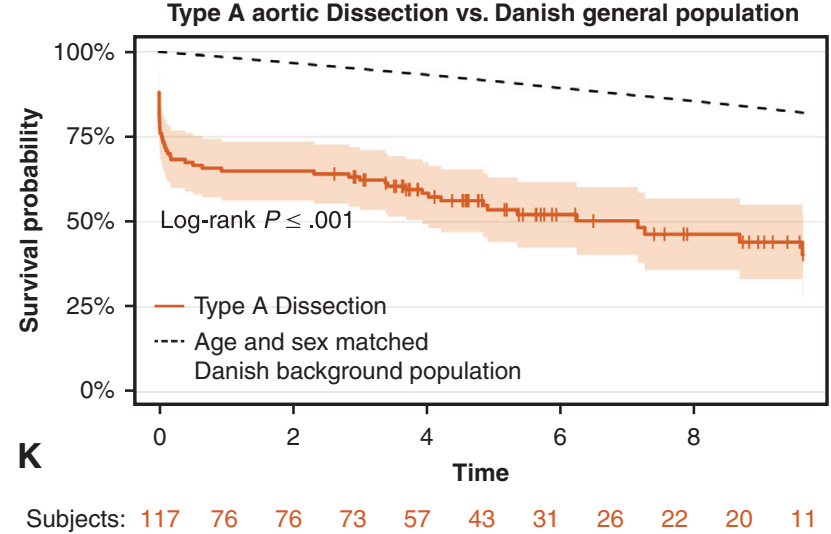

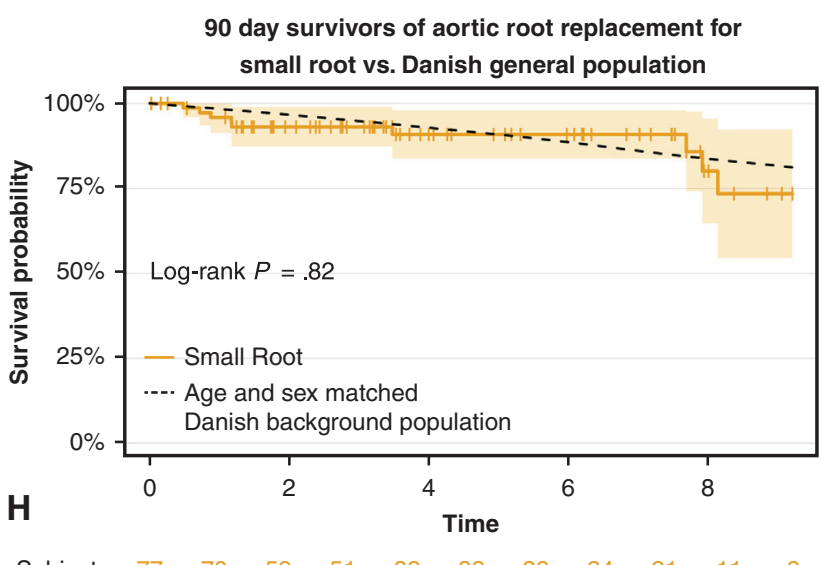

90 day survivors of aortic root replacement for other vs. Danish general population

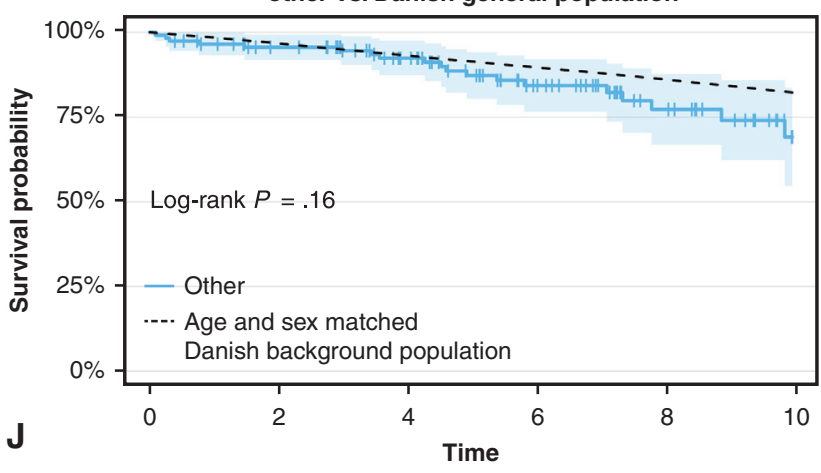

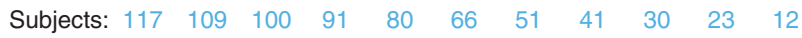

90 day survivors of aortic root replacement for Type A aortic Dissection vs. Danish general population

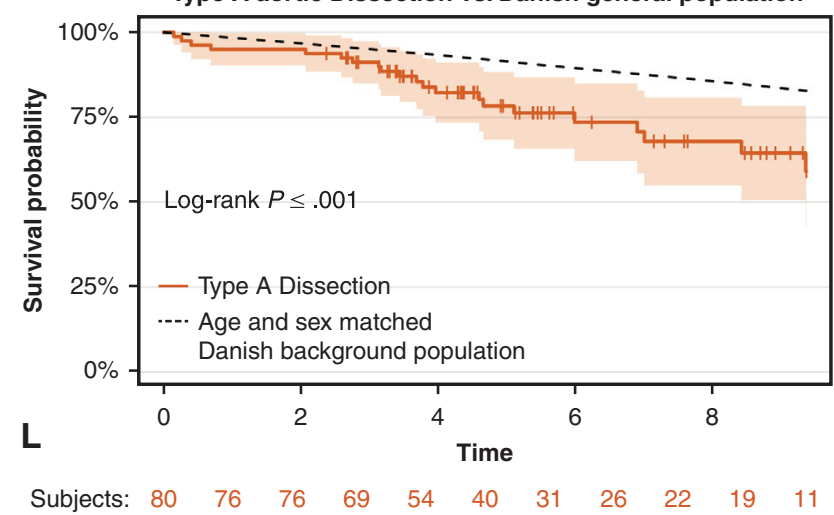

FIGURE E2. (Continued). 

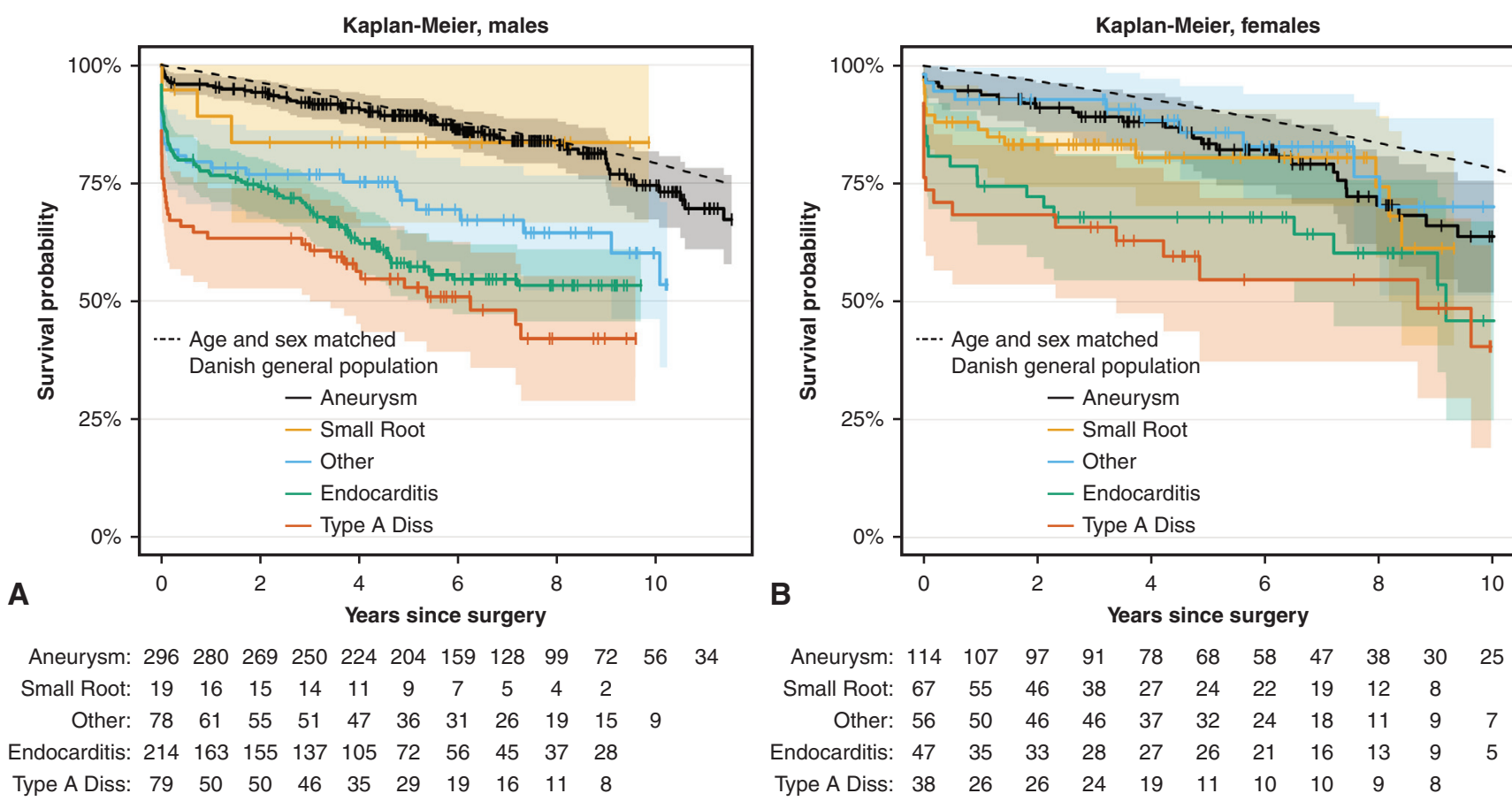

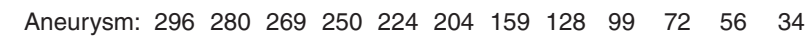

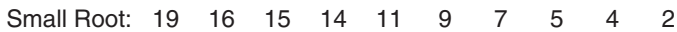

Other: $\begin{array}{lllllllllll}78 & 61 & 55 & 51 & 47 & 36 & 31 & 26 & 19 & 15 & 9\end{array}$

Endocarditis: $214 \quad 163 \quad 155 \quad 137 \quad 105 \quad 72 \quad 56 \quad 45 \quad 37 \quad 28$

Type A Diss: $\begin{array}{llllllllll}79 & 50 & 50 & 46 & 35 & 29 & 19 & 16 & 11 & 8\end{array}$

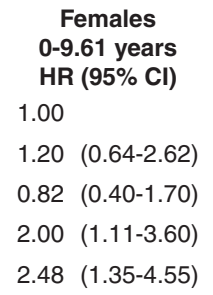

$\begin{array}{ll}1.00 & \\ 1.05 & (0.54-2.03) \\ 0.87 & (0.42-1.84) \\ 2.02 & (1.08-3.76) \\ 3.21 & (1.66-6.20)\end{array}$

C

Males
0-9.61 years
HR $(95 \% \mathrm{Cl})$
1.00
$1.13 \quad(0.35-3.64)$
$2.36(1.46-3.83)$
$3.31 \quad(2.33-4.70)$
$4.50 \quad(2.96-6.84)$

$\begin{array}{ll}1.00 & \\ 1.37 & (0.42-4.46) \\ 2.48 & (1.53-4.04) \\ 3.36 & (2.32-4.86) \\ 4.30 & (2.79-6.61)\end{array}$

FIGURE E3. Survival according to sex. In this study of 1008 patients who had undergone aortic root replacement with the Freestyle (Medtronic Inc, Minneapolis, Minn) bioprosthesis we investigated intermediate-term survival. In this study, an excessive mortality in patients who were operated for type A aortic dissection and endocarditis was shown, but a survival close to the general population in the primarily elective indications of aneurysm, small root, and "other" (consisting among other things of reoperative surgery and bailout surgery for failed aortic valve or root procedures). A subgroup analysis of men (A) and women (B) showed similar trends for both sexes. It appears as though female survival rates might be lower than that of the age- and sexstandardized general population, but because the confidence interval $(C I)$ of all of the elective indications overlaps the curve of the general population for most of the period, this is not certain. A difference between sexes is shown in the group "others," however, taking into consideration the heterogenicity and low number of patients in this group, this alone cannot be interpreted as a true sex-mediated difference (C shows hazard ratios $[H R s]$ obtained using Cox proportional hazards regression analysis per sex). The excessive mortality in the group "endocarditis" might be less pronounced in the female group but is nonetheless significantly worse than for aneurysm patients, in accordance with the male group (C). Further research is needed to further understand the influence of sex on aortic root replacement with the Freestyle bioprosthesis. Diss, Dissection; $a$-fib, atrial fibrillation; $e G F R$, estimated glomerular filtration rate. 
Death before valve-related (I) and coronary reintervention (II) respectively - as competing risk in Aalen-Johnson model.
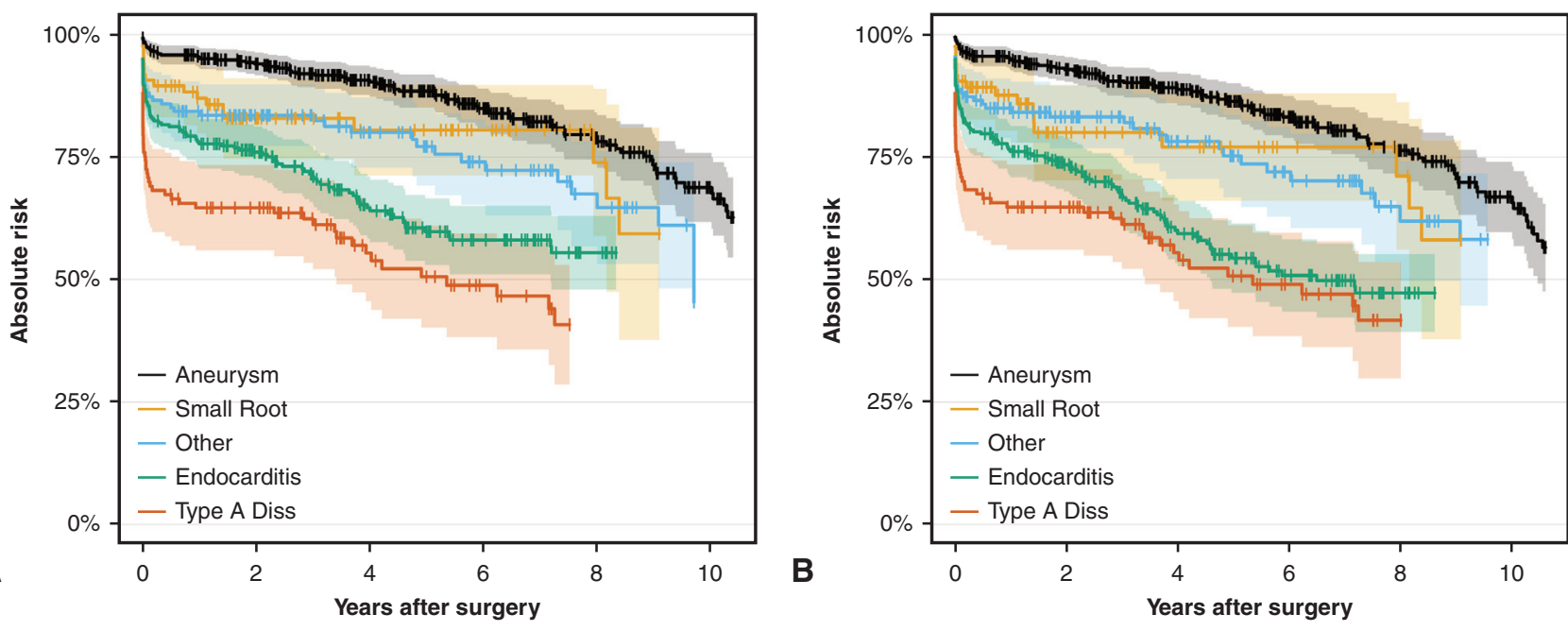

$\begin{array}{rccccccccccc}\text { Aneurysm: } & 410 & 370 & 334 & 287 & 240 & 201 & 155 & 119 & 98 & 69 & 41 \\ \text { Small Root: } & 86 & 66 & 45 & 36 & 32 & 30 & 20 & 15 & 9 & 0 & 0 \\ \text { Other: } & 134 & 102 & 82 & 70 & 56 & 44 & 37 & 29 & 20 & 15 & 0 \\ \text { Endocarditis: } & 261 & 179 & 149 & 115 & 87 & 62 & 51 & 36 & 26 & 0 & 0 \\ \text { Type A Diss: } & 117 & 70 & 62 & 47 & 32 & 26 & 20 & 11 & 0 & 0 & 0\end{array}$

$\begin{array}{rccccccccccc}\text { Aneurysm: } & 408 & 362 & 325 & 279 & 228 & 190 & 147 & 114 & 96 & 65 & 39 \\ \text { Small Root: } & 84 & 49 & 31 & 27 & 24 & 19 & 14 & 14 & 8 & 0 & 0 \\ \text { Other: } & 134 & 98 & 81 & 67 & 54 & 44 & 35 & 26 & 19 & 14 & 0 \\ \text { Endocarditis: } & 258 & 183 & 148 & 116 & 88 & 64 & 50 & 35 & 24 & 0 & 0 \\ \text { Type A Diss: } & 117 & 71 & 62 & 47 & 32 & 29 & 21 & 14 & 0 & 0 & 0\end{array}$

FIGURE E4. Death before (A) valve-related and (B) coronary reintervention, as competing risk in the Aalen-Johnson model. Curves of “cause-2”" (ie, death) from competing risk analyses of reinterventions after aortic root replacement with the Freestyle (Medtronic Inc, Minneapolis, Minn) bioprosthesis. Curves are truncated at $10 \%$ of the group population remaining at risk, censor times are marked with ticks and $95 \%$ confidence interval is indicated by shading. See Figure 2 for inverted cumulative incidence curves for (A) valve-related reinterventions and (B) coronary reinterventions. Aneurysm indicates aortic root aneurysm, small root indicates patients with aortic valve lesion at risk for patient-prosthesis mismatch, other represents primarily reoperative cases (with eg, aortic valve dysfunction, and bail-out for eg, aortic valve plasties), and endocarditis indicates complex endocarditis such as prosthetic endocarditis or root abscess. Diss, Dissection. 
TABLE E1. Preoperative patient characteristics according to indication, including missing data

\begin{tabular}{|c|c|c|c|c|c|c|}
\hline$\%$ (n) & $\frac{\text { Aneurysm }}{100(410)}$ & $\frac{\text { Small root }}{100(86)}$ & $\frac{\text { Other }}{100(142)}$ & $\frac{\text { Endocarditis }}{100(275)}$ & $\frac{\text { Type A dissection }}{100(117)}$ & $\frac{\text { All }}{100(1030)}$ \\
\hline \multicolumn{7}{|l|}{ Age at surgery } \\
\hline Median (IQR), y & $67(61-72)$ & $68(58.2-73.0)$ & $65(55.2-71.0)$ & $63(51.5-71.0)$ & $66(60-71)$ & $66(58.0-71.8)$ \\
\hline Range, y & $22-85$ & $18-84$ & $24-86$ & $14-86$ & 33-82 & $14-86$ \\
\hline Missing, $\mathrm{n}$ & 0 & 0 & 0 & 0 & 0 & 0 \\
\hline Age $<60$ y & $22.4(92)$ & $26.7(23)$ & $42.3(60)$ & $42.2(116)$ & $27.4(32)$ & $31.4(323)$ \\
\hline Male sex & $72.2(296)$ & $22.1(19)$ & $57.7(82)$ & $81.8(225)$ & $67.5(79)$ & $68.1(701)$ \\
\hline Missing, $\mathrm{n}$ & 0 & 0 & 0 & 0 & 0 & 0 \\
\hline \multicolumn{7}{|l|}{ BMI } \\
\hline$<20$ & $5.2(21)$ & $5.9(5)$ & $4.4(6)$ & $5.3(14)$ & $6.4(7)$ & $5.3(53)$ \\
\hline $20-30$ & $77.9(313)$ & $65.9(56)$ & $67.2(92)$ & $75.3(198)$ & $78.2(86)$ & $74.7(745)$ \\
\hline$>30$ & $16.9(68)$ & $28.2(24)$ & $28.5(39)$ & $19.4(51)$ & $15.5(17)$ & $20.0(199)$ \\
\hline Missing, $\mathrm{n}$ & 8 & 1 & 5 & 12 & 7 & 33 \\
\hline Median eGFR (IQR), $\mathrm{mL} / \mathrm{min}$ & 78 (64.9-97.6) & $71(56.4-85.3)$ & $75.4(61.2-97.1)$ & $77.4(52.7-90.0)$ & $71.8(57.5-82.0)$ & $76(60-90)$ \\
\hline Missing, $\mathrm{n}$ & 7 & 1 & 0 & 8 & 4 & 20 \\
\hline Dialysis & $0.2(1)$ & $1.2(1)$ & $0.7(1)$ & $8.1(22)$ & $0.9(1)$ & $2.5(26)$ \\
\hline Missing, $\mathrm{n}$ & 0 & 0 & 2 & 4 & 0 & 6 \\
\hline Diabetes mellitus & $5.9(24)$ & $15.1(13)$ & $9.9(14)$ & $14.0(38)$ & $3.4(4)$ & $9.1(93)$ \\
\hline Missing, $\mathrm{n}$ & 1 & 0 & 0 & 4 & 0 & 5 \\
\hline Insulin-dependent diabetes & $1.5(6)$ & $3.5(3)$ & $2.8(4)$ & $2.6(7)$ & $0.9(1)$ & $2.0(21)$ \\
\hline Missing, $\mathrm{n}$ & 1 & 0 & 0 & 4 & 0 & 5 \\
\hline Hypertension & $65.0(265)$ & $59.3(51)$ & $63.4(90)$ & $51.9(137)$ & $60.3(70)$ & $60.3(613)$ \\
\hline Missing, $\mathrm{n}$ & 0 & 0 & 0 & 0 & 0 & 0 \\
\hline Hypercholesterolemia & $42.8(161)$ & $52.9(45)$ & $48.2(67)$ & $35.4(87)$ & $30.5(32)$ & $41.2(392)$ \\
\hline Missing, $\mathrm{n}$ & 34 & 1 & 3 & 29 & 12 & 79 \\
\hline Atrial fibrillation & $17.8(73)$ & $14.1(12)$ & $22.9(32)$ & $27.0(70)$ & $16.2(19)$ & $20.4(206)$ \\
\hline Missing, $\mathrm{n}$ & 1 & 1 & 2 & 16 & 0 & 20 \\
\hline Coronary artery disease & $23.3(94)$ & 33.7 (29) & $29.7(41)$ & $21.7(57)$ & $12.2(14)$ & $23.4(235)$ \\
\hline Missing, $\mathrm{n}$ & 6 & 0 & 4 & 12 & 2 & 24 \\
\hline Chronic lung disease & $13.3(54)$ & $15.3(13)$ & $11.3(16)$ & $9.6(26)$ & $14.5(17)$ & $12.3(126)$ \\
\hline Missing, $\mathrm{n}$ & 4 & 1 & 0 & 4 & 0 & 9 \\
\hline $\begin{array}{l}\text { Previous cerebrovascular } \\
\quad \text { disease }\end{array}$ & $9.0(37)$ & $14.0(12)$ & $14.9(21)$ & $24.3(66)$ & $15.4(18)$ & $15.0(154)$ \\
\hline Missing, $\mathrm{n}$ & 0 & 0 & 1 & 3 & 0 & 4 \\
\hline Peripheral vascular disease & $4.6(19)$ & $9.3(8)$ & $6.4(9)$ & $5.2(14)$ & $5.1(6)$ & $5.5(56)$ \\
\hline Missing, $\mathrm{n}$ & 0 & 0 & 1 & 5 & 0 & 6 \\
\hline Bicuspid valve & 40.9 (167) & $15.1(13)$ & $15.9(22)$ & $14.3(39)$ & $7.7(9)$ & $24.5(250)$ \\
\hline Missing, $\mathrm{n}$ & 2 & 0 & 4 & 2 & 0 & 8 \\
\hline Previous cardiac surgery & $9.3(38)$ & $9.3(8)$ & $73.9(105)$ & $68.6(188)$ & $9.5(11)$ & $34.0(350)$ \\
\hline Aortic surgery & $8.3(34)$ & $2.4(2)$ & $64.8(92)$ & $64.2(176)$ & $7.8(9)$ & $30.5(313)$ \\
\hline CABG & $1.2(5)$ & $0.0(0)$ & $10.6(15)$ & $8.5(23)$ & $1.7(2)$ & $4.4(45)$ \\
\hline Other & $0.2(1)$ & $7.0(6)$ & $7.0(10)$ & $4.4(12)$ & $0.0(0)$ & $2.8(29)$ \\
\hline Missing, $\mathrm{n}$ & 0 & 0 & 0 & 1 & 1 & 2 \\
\hline History of endocarditis & $1.7(7)$ & $0.0(0)$ & $14.8(21)$ & $28.2(77)$ & $0.9(1)$ & $10.3(106)$ \\
\hline Missing, $\mathrm{n}$ & 0 & 0 & 0 & 2 & 1 & 3 \\
\hline
\end{tabular}

Data are presented as \% (n) except where otherwise noted. $I Q R$, Interquartile range; $B M I$, body mass index; $e G F R$, estimated glomerular filtration rate; $C A B G$, coronary artery bypass graft. 
TABLE E2. Preoperative patient characteristics according to indication and sex: men

\begin{tabular}{|c|c|c|c|c|c|c|c|}
\hline $\mathbf{N}(\%)$ & $\begin{array}{c}\text { Aneurysm } \\
296(100)\end{array}$ & $\frac{\text { Small root }}{19(100)}$ & $\begin{array}{c}\text { Other } \\
82(100)\end{array}$ & $\frac{\text { Endocarditis }}{225(100)}$ & $\begin{array}{c}\begin{array}{c}\text { Type A } \\
\text { dissection }\end{array} \\
79(100)\end{array}$ & $\frac{\text { All }}{701(100)}$ & $P$ value \\
\hline \multicolumn{8}{|l|}{ Age at surgery } \\
\hline Median (IQR), y & $66(60-70)$ & $58(51.0-67.5)$ & $65(57.0-70.8)$ & $63(50-71)$ & $65(60-70)$ & $65(58-70)$ & .0002 \\
\hline Range & $22-85$ & $18-78$ & 24-82 & $14-86$ & $37-82$ & $14-86$ & \\
\hline Missing, $\mathrm{n}$ & 0 & 0 & 0 & 0 & 0 & 0 & \\
\hline Age $<60$ y & $25.3(75)$ & $57.9(11)$ & $41.5(34)$ & $42.7(96)$ & $26.6(21)$ & $33.8(237)$ & $<.0001$ \\
\hline $\begin{array}{l}\text { Median BMI continuous } \\
\quad(\mathrm{IQR})\end{array}$ & $26.6(23.8-28.8)$ & $25.1(23.4-28.7)$ & $27.0(23.1-29.1)$ & $25.7(23.1-29.1)$ & $25.8(23.9-28.0)$ & $26.2(23.7-29.0)$ & .04 \\
\hline \multicolumn{8}{|l|}{ BMI categorical } \\
\hline$<20$ & $3.4(10)$ & $5.3(1)$ & $1.2(1)$ & $5.1(11)$ & $6.8(5)$ & $4.1(28)$ & \\
\hline $20-30$ & $79.0(229)$ & $73.7(14)$ & $65.0(52)$ & $73.1(158)$ & $80.8(59)$ & $75.5(512)$ & \\
\hline$>30$ & $17.6(51)$ & $21.1(4)$ & $33.8(27)$ & $21.8(47)$ & $12.3(9)$ & $20.4(138)$ & \\
\hline Missing, $\mathrm{n}$ & 6 & 0 & 2 & 9 & 6 & 23 & \\
\hline Median eGFR (IQR), $\mathrm{mL} / \mathrm{min}$ & $83.8(68.8-103.1)$ & $83.3(72.0-95.2)$ & $84(64.1-101.8)$ & $78(53-90)$ & $72(57.2-82.0)$ & $79.8(62.3-97.3)$ & .0001 \\
\hline Missing, $\mathrm{n}$ & 4 & 0 & 0 & 5 & 4 & 13 & \\
\hline Dialysis & $0.0(0)$ & $5.3(1)$ & $0.0(0)$ & $6.7(15)$ & $1.3(1)$ & $2.4(17)$ & $<.0001$ \\
\hline Missing, $\mathrm{n}$ & 0 & 0 & 2 & 2 & 0 & 4 & \\
\hline Diabetes mellitus & $5.1(15)$ & $15.8(3)$ & $8.5(7)$ & $14.7(33)$ & $5.1(4)$ & $8.9(62)$ & .002 \\
\hline Missing, $\mathrm{n}$ & 1 & 0 & 0 & 1 & 0 & 2 & \\
\hline Insulin-dependent diabetes & $1.0(3)$ & $0.0(0)$ & $1.2(1)$ & $3.1(7)$ & $1.3(1)$ & $1.7(12)$ & .40 \\
\hline Missing, $\mathrm{n}$ & 1 & 0 & 0 & 1 & 0 & 2 & \\
\hline Hypertension & $64.6(190)$ & $36.8(7)$ & $68.3(56)$ & $51.8(113)$ & $63.3(50)$ & $60.1(416)$ & .02 \\
\hline Missing, $\mathrm{n}$ & 0 & 0 & 0 & 0 & 0 & 0 & \\
\hline Hypercholesterolemia & $43.0(117)$ & $36.8(7)$ & $48.1(39)$ & $34.5(70)$ & $30.6(22)$ & $39.4(255)$ & .07 \\
\hline Missing, $\mathrm{n}$ & 24 & 0 & 1 & 22 & 7 & 54 & \\
\hline Atrial fibrillation & $18.6(55)$ & $10.5(2)$ & $20.0(16)$ & $27.8(59)$ & $17.7(14)$ & $21.3(146)$ & .07 \\
\hline Missing, $\mathrm{n}$ & 0 & 0 & 2 & 13 & 0 & 15 & \\
\hline Coronary artery disease & $25.4(74)$ & $21.1(4)$ & $38.3(31)$ & $22.2(48)$ & $15.6(12)$ & 24.7 (169) & .01 \\
\hline Missing, $\mathrm{n}$ & 5 & 0 & 1 & 9 & 2 & 17 & \\
\hline Chronic lung disease & $11.3(33)$ & $0.0(0)$ & $12.2(10)$ & $9.8(22)$ & $12.7(10)$ & $10.8(75)$ & .55 \\
\hline Missing, $\mathrm{n}$ & 4 & 0 & 0 & 1 & 0 & 5 & \\
\hline $\begin{array}{l}\text { Previous cerebrovascular } \\
\text { disease }\end{array}$ & $9.5(28)$ & $5.3(1)$ & $15.9(13)$ & $21.9(49)$ & $11.4(9)$ & $14.3(100)$ & .001 \\
\hline Missing, $\mathrm{n}$ & 0 & 0 & 0 & 1 & 0 & 1 & \\
\hline Peripheral vascular disease & $5.4(16)$ & $5.3(1)$ & $6.1(5)$ & $5.8(13)$ & $6.3(5)$ & $5.7(40)$ & 1.00 \\
\hline Missing, $\mathrm{n}$ & 0 & 0 & 0 & 2 & 0 & 2 & \\
\hline Bicuspid valve & $42.5(125)$ & $36.8(7)$ & $18.5(15)$ & $16.6(37)$ & $10.1(8)$ & $27.6(192)$ & $<.0001$ \\
\hline Missing, $\mathrm{n}$ & 2 & 0 & 1 & 2 & 0 & 5 & \\
\hline Previous cardiac surgery & $10.5(31)$ & $15.8(3)$ & $72.0(59)$ & $67.4(151)$ & $14.1(11)$ & $36.5(255)$ & $<.0001$ \\
\hline Aortic surgery & $9.5(28)$ & $0.0(0)$ & $63.4(52)$ & $63.4(142)$ & $11.5(9)$ & $33.1(231)$ & \\
\hline CABG & $1.0(3)$ & $0.0(0)$ & $14.6(12)$ & $9.0(20)$ & $2.5(2)$ & $5.3(37)$ & \\
\hline Other & $0.3(1)$ & $15.8(3)$ & $4.9(4)$ & $4.0(9)$ & $0.0(0)$ & $2.4(17)$ & \\
\hline Missing, $\mathrm{n}$ & 0 & 0 & 0 & 1 & 1 & 2 & \\
\hline History of endocarditis & $1.4(4)$ & $0.0(0)$ & $19.5(16)$ & $29.9(67)$ & $1.3(1)$ & $12.6(88)$ & $<.0001$ \\
\hline Missing, $\mathrm{n}$ & 0 & 0 & 0 & 1 & 1 & 2 & \\
\hline
\end{tabular}

Data are presented as \% (n) except where otherwise noted. $I Q R$, Interquartile range; $B M I$, body mass index; $e G F R$, estimated glomerular filtration rate; $C A B G$, coronary artery bypass graft. 
TABLE E3. Preoperative patient characteristics according to indication and sex: women

\begin{tabular}{|c|c|c|c|c|c|c|c|}
\hline N (\%) & $\begin{array}{c}\text { Aneurysm } \\
114(100)\end{array}$ & $\frac{\text { Small root }}{69(100)}$ & $\begin{array}{c}\text { Other } \\
63(100)\end{array}$ & $\frac{\text { Endocarditis }}{50(100)}$ & $\begin{array}{c}\begin{array}{c}\text { Type A } \\
\text { dissection }\end{array} \\
38(100)\end{array}$ & $\frac{\text { All }}{329(100)}$ & $P$ value \\
\hline \multicolumn{8}{|l|}{ Age at surgery $[y]$} \\
\hline Median (IQR) & $68(64-74)$ & $69(62.0-74.5)$ & $63(54.8-72.0)$ & $63.5(54.5-70.8)$ & $67(59.0-72.5)$ & $68(59-73)$ & .0008 \\
\hline Range & 37-83 & 19-84 & $31-86$ & 25-84 & $33-77$ & 19-86 & \\
\hline Missing, $\mathrm{n}$ & 0 & 0 & 0 & 0 & 0 & 0 & \\
\hline Age $<60 y$ & $14.9(17)$ & $17.9(12)$ & $43.3(26)$ & $40.0(20)$ & $28.9(11)$ & $26.1(86)$ & $<.0001$ \\
\hline $\begin{array}{l}\text { Median BMI continuous } \\
\text { (IQR) }\end{array}$ & $25(22-28)$ & $26.4(23.6-30.9)$ & $24(21.4-28.8)$ & $24.2(22.3-28.7)$ & $24.5(22.3-29.4)$ & $24.8(22.2-28.9)$ & .002 \\
\hline BMI categorical & & & & & & & .18 \\
\hline$<20$ & 9.8 (11) & $6.1(4)$ & $8.8(5)$ & $6.4(3)$ & $5.4(2)$ & $7.8(25)$ & \\
\hline $20-30$ & $75.0(84)$ & $63.6(42)$ & $70.2(40)$ & $85.1(40)$ & $73.0(27)$ & $73.0(233)$ & \\
\hline$>30$ & $15.2(17)$ & $30.3(20)$ & $21.1(12)$ & $8.5(4)$ & $21.6(8)$ & $19.1(61)$ & \\
\hline Missing, $\mathrm{n}$ & 2 & 1 & 3 & 3 & 1 & 10 & \\
\hline Median eGFR (IQR), $\mathrm{mL} / \mathrm{min}$ & $68.4(55.0-85.7)$ & $68.4(56.1-83.0)$ & $69.6(57.8-90.0)$ & $66.2(51.6-90.0)$ & $71.4(59.2-83.8)$ & $68.6(55.7-86.9)$ & .66 \\
\hline Missing, $\mathrm{n}$ & 3 & 1 & 0 & 3 & 0 & 7 & \\
\hline Dialysis & $0.9(1)$ & $0.0(0)$ & $1.7(1)$ & $14.6(7)$ & $0.0(0)$ & $2.8(9)$ & $<.0001$ \\
\hline Missing, $\mathrm{n}$ & 0 & 0 & 0 & 2 & 0 & 2 & \\
\hline Diabetes mellitus & $7.9(9)$ & $14.9(10)$ & $11.7(7)$ & $10.6(5)$ & $0.0(0)$ & $9.5(31)$ & .14 \\
\hline Missing, $\mathrm{n}$ & 0 & 0 & 0 & 3 & 0 & 3 & \\
\hline Insulin-dependent diabetes & $2.6(3)$ & $4.5(3)$ & $5.0(3)$ & $0.0(0)$ & $0.0(0)$ & $2.8(9)$ & .37 \\
\hline Missing, $\mathrm{n}$ & 0 & 0 & 0 & 3 & 0 & 3 & \\
\hline Hypertension & $65.8(75)$ & 65.7 (44) & 56.7 (34) & $52.2(24)$ & $54.1(20)$ & 60.8 (197) & . 004 \\
\hline Missing, $\mathrm{n}$ & 0 & 0 & 0 & 0 & 0 & 0 & \\
\hline Hypercholesterolemia & $42.3(44)$ & $57.6(38)$ & $48.3(28)$ & 39.5 (17) & $30.3(10)$ & $45.1(137)$ & .09 \\
\hline Missing, $\mathrm{n}$ & 10 & 1 & 2 & 7 & 5 & 25 & \\
\hline Atrial fibrillation & $15.9(18)$ & $15.2(10)$ & $26.7(16)$ & $23.4(11)$ & $13.2(5)$ & $18.5(60)$ & .28 \\
\hline Missing, $\mathrm{n}$ & 1 & 1 & 0 & 3 & 0 & 5 & \\
\hline Coronary artery disease & $17.7(20)$ & $37.3(25)$ & $17.5(10)$ & $19.1(9)$ & $5.3(2)$ & $20.5(66)$ & .001 \\
\hline Missing, $\mathrm{n}$ & 1 & 0 & 3 & 3 & 0 & 7 & \\
\hline Chronic lung disease & $18.4(21)$ & $19.7(13)$ & $10.0(6)$ & $8.5(4)$ & $18.4(7)$ & $15.7(51)$ & .29 \\
\hline Missing, $\mathrm{n}$ & 0 & 1 & 0 & 3 & 0 & 4 & \\
\hline $\begin{array}{l}\text { Previous cerebrovascular } \\
\text { disease }\end{array}$ & $7.9(9)$ & $16.4(11)$ & $13.6(8)$ & $35.4(17)$ & $23.7(9)$ & $16.6(54)$ & .0004 \\
\hline Missing, $\mathrm{n}$ & 0 & 0 & 1 & 2 & 0 & 3 & \\
\hline Peripheral vascular disease & $2.6(3)$ & $10.4(7)$ & $6.8(4)$ & $2.1(1)$ & $2.6(1)$ & $4.9(16)$ & .12 \\
\hline Missing, $\mathrm{n}$ & 0 & 0 & 1 & 3 & 0 & 4 & \\
\hline Bicuspid valve & $36.8(42)$ & $9.0(6)$ & $12.3(7)$ & $4.0(2)$ & $2.6(1)$ & $17.8(58)$ & $<.0001$ \\
\hline Missing, $\mathrm{n}$ & 0 & 0 & 3 & 0 & 0 & 3 & \\
\hline Previous cardiac surgery & $6.1(7)$ & $7.5(5)$ & $76.7(46)$ & $74.0(37)$ & $0.0(0)$ & $28.9(95)$ & $<.0001$ \\
\hline Aortic surgery & $5.3(6)$ & $3.0(2)$ & $66.7(40)$ & $68.0(34)$ & $0.0(0)$ & $24.9(82)$ & \\
\hline CABG & $1.8(2)$ & $0.0(0)$ & $5.0(3)$ & $6.2(3)$ & $0.0(0)$ & $2.4(8)$ & \\
\hline Other & $0.0(0)$ & $4.5(3)$ & $10.0(6)$ & $6.0(3)$ & $0.0(0)$ & $3.6(12)$ & \\
\hline Missing, $\mathrm{n}$ & 0 & 0 & 0 & 0 & 0 & 0 & \\
\hline History of endocarditis & $2.6(3)$ & $0.0(0)$ & $8.3(5)$ & $20.4(10)$ & $0.0(0)$ & $5.5(18)$ & $<.0001$ \\
\hline Missing, $\mathrm{n}$ & 0 & 0 & 0 & 1 & 0 & 1 & \\
\hline
\end{tabular}

$I Q R$, Interquartile range; $B M I$, body mass index; $e G F R$, estimated glomerular filtration rate; $C A B G$, coronary artery bypass graft. 
TABLE E4. Surgical characteristics according to indication, including missing data

\begin{tabular}{|c|c|c|c|c|c|c|}
\hline$\%(n)$ & $\frac{\text { Aneurysm }}{100(410)}$ & $\frac{\text { Small root }}{100(86)}$ & $\begin{array}{c}\text { Other } \\
100(142)\end{array}$ & $\frac{\text { Endocarditis }}{100(275)}$ & $\frac{\text { Type A dissection }}{100(117)}$ & $\frac{\text { All }}{100(1030)}$ \\
\hline $\begin{array}{l}\text { Isolated aortic root } \\
\text { replacement }\end{array}$ & $20.6(84)$ & $45.3(39)$ & $45.1(64)$ & 40.7 (111) & $4.3(5)$ & $29.5(303)$ \\
\hline Concomitant procedure & $79.4(324)$ & $54.7(47)$ & $54.9(78)$ & $59.3(162)$ & 95.7 (112) & $70.5(723)$ \\
\hline Asc ao only & $44.6(182)$ & $9.3(8)$ & $15.5(22)$ & $9.5(26)$ & $46.2(54)$ & $28.5(292)$ \\
\hline $\begin{array}{l}\text { CABG (with or without asc } \\
\text { ao) }\end{array}$ & $12.3(50)$ & $25.6(22)$ & $15.5(22)$ & $10.3(28)$ & $17.1(20)$ & $13.8(142)$ \\
\hline Aortic arch surgery & $10.8(44)$ & $1.2(1)$ & $2.8(4)$ & $2.2(6)$ & $24.8(29)$ & $8.2(84)$ \\
\hline Other & $13.3(54)$ & $18.6(16)$ & $22.0(31)$ & 37.7 (103) & $9.4(11)$ & $21.0(215)$ \\
\hline Missing, $\mathrm{n}$ & 2 & 0 & 0 & 2 & 0 & 4 \\
\hline \multicolumn{7}{|l|}{ Implanted valve size in $\mathrm{mm}$} \\
\hline 19 & $0.0(0)$ & $5.8(5)$ & $1.4(2)$ & $1.1(3)$ & $0.9(1)$ & $1.1(11)$ \\
\hline 21 & $2.7(11)$ & $32.6(28)$ & $17.6(25)$ & $7.3(20)$ & $6.0(7)$ & $8.8(91)$ \\
\hline 23 & $12.0(49)$ & $44.2(38)$ & $26.8(38)$ & $22.2(61)$ & $20.5(24)$ & $20.4(210)$ \\
\hline 25 & $24.1(99)$ & $12.8(11)$ & $28.9(41)$ & $31.6(87)$ & $33.3(39)$ & 26.9 (277) \\
\hline 27 & $36.6(150)$ & $4.7(4)$ & $14.8(21)$ & $21.1(58)$ & $27.4(32)$ & $25.7(265)$ \\
\hline 29 & $23.4(96)$ & $0.0(0)$ & $5.6(8)$ & $9.5(26)$ & $8.5(10)$ & $13.6(140)$ \\
\hline Not noted & $1.2(5)$ & $0.0(0)$ & $4.9(7)$ & $7.3(20)$ & $3.4(4)$ & $3.5(36)$ \\
\hline \multicolumn{7}{|c|}{ Suture technique, proximal Freestyle anastomosis } \\
\hline Running & $57.3(235)$ & $79.1(68)$ & $47.9(68)$ & $45.1(124)$ & $41.9(49)$ & $52.8(544)$ \\
\hline Pledgeted U-sutures & $36.1(148)$ & $14.0(12)$ & $33.8(48)$ & $26.5(73)$ & $53.8(63)$ & $33.4(344)$ \\
\hline Other & $4.4(18)$ & $4.7(4)$ & $11.3(16)$ & $18.2(50)$ & $1.7(2)$ & $8.7(90)$ \\
\hline Not noted & $2.2(9)$ & $2.3(2)$ & $7.0(10)$ & $10.2(28)$ & $2.6(3)$ & $5.0(52)$ \\
\hline $\begin{array}{l}\text { Median cross-clamp time } \\
\text { (IQR), min }\end{array}$ & $116(95-138)$ & $109(86-135)$ & $147(112-186)$ & $160(122-198)$ & $155(123-188)$ & $130(103-172)$ \\
\hline $\begin{array}{l}\text { Isolated aortic root } \\
\text { replacement }\end{array}$ & $104(88-120)$ & $88(77-112)$ & $123(102-171)$ & $127(109-158)$ & $122(122-134)$ & $116(92-142)$ \\
\hline Concomitant asc ao only & $112(95-131)$ & $116(97-123)$ & $156(130-185)$ & $182(161-222)$ & $143(121-173)$ & $123(101-152)$ \\
\hline $\begin{array}{l}\text { Concomitant CABG (with } \\
\text { or without asc ao) }\end{array}$ & $133(114-172)$ & $122(104-150)$ & $134(123-173)$ & $174(149-200)$ & $161(120-219)$ & $144(117-180)$ \\
\hline $\begin{array}{l}\text { Concomitant aortic arch } \\
\text { surgery }\end{array}$ & $122(102-162)$ & $85(85-85)$ & $266(247-278)$ & $180(160-193)$ & $163(144-223)$ & $152(118-188)$ \\
\hline $\begin{array}{l}\text { Other concomitant } \\
\text { procedure }\end{array}$ & $129(90-171)$ & $136(109-152)$ & $177(148-216)$ & $192(142-235)$ & $163(147-187)$ & $166(125-215)$ \\
\hline Missing, $\mathrm{n}$ & 4 & 0 & 5 & 10 & 2 & 21 \\
\hline Median CPB time (IQR), min & $150(124-187)$ & $139(110-184)$ & $196(155-264)$ & $225(176-287)$ & $255(206-317)$ & $181(139-246)$ \\
\hline $\begin{array}{l}\text { Isolated aortic root } \\
\text { replacement }\end{array}$ & $125(113-163)$ & $109(95-137)$ & $175(143-230)$ & $180(149-228)$ & $175(170-233)$ & $166(121-201)$ \\
\hline Concomitant asc ao only & $144(124-166)$ & $136(117-148)$ & $205(149-269)$ & $250(196-281)$ & $242(201-281)$ & $162(132-217)$ \\
\hline $\begin{array}{l}\text { Concomitant CABG (with } \\
\text { or without asc ao) }\end{array}$ & $179(147-247)$ & $179(147-204)$ & $192(181-243)$ & $254(215-298)$ & $309(210-399)$ & $211(160-280)$ \\
\hline $\begin{array}{l}\text { Concomitant aortic arch } \\
\text { surgery }\end{array}$ & $191(149-236)$ & $152(152-152)$ & $337(325-365)$ & $328(289-362)$ & $263(215-340)$ & $235(177-314)$ \\
\hline $\begin{array}{l}\text { Other concomitant } \\
\text { procedure }\end{array}$ & $177(130-220)$ & $168(133-198)$ & $256(185-313)$ & $260(201-344)$ & $305(269-370)$ & $228(170-308)$ \\
\hline Missing, $n$ & 4 & 0 & 5 & 10 & 2 & 21 \\
\hline
\end{tabular}

Data are presented as \% (n) except where otherwise noted. Freestyle bioprosthesis is from Medtronic Inc (Minneapolis, Minn). asc ao, Ascending aorta; $C A B G$, coronary artery bypass graft; $I Q R$, interquartile range; $C P B$, cardiopulmonary bypass. 